Florida International University

FIU Digital Commons

$12-2019$

\title{
Taking Apart the Time Machine: Investigating Space-for-Time Substitution Modeling in the Florida Everglades
}

Theresa Kelly Brown

Florida International University, thbrown@fiu.edu

Follow this and additional works at: https://digitalcommons.fiu.edu/etd

Part of the Biodiversity Commons, and the Terrestrial and Aquatic Ecology Commons

\section{Recommended Citation}

Brown, Theresa Kelly, "Taking Apart the Time Machine: Investigating Space-for-Time Substitution Modeling in the Florida Everglades" (2019). FIU Electronic Theses and Dissertations. 4380.

https://digitalcommons.fiu.edu/etd/4380

This work is brought to you for free and open access by the University Graduate School at FIU Digital Commons. It has been accepted for inclusion in FIU Electronic Theses and Dissertations by an authorized administrator of FIU Digital Commons. For more information, please contact dcc@fiu.edu. 


\section{FLORIDA INTERNATIONAL UNIVERSITY}

Miami, Florida

TAKING APART THE TIME MACHINE:

INVESTIGATING SPACE-FOR-TIME SUBSTITUTION MODELING IN THE FLORIDA EVERGLADES

A thesis submitted in partial fulfillment of the requirements for the degree of MASTER OF SCIENCE

in

BIOLOGY

by

Theresa Kelly Brown 
To: Dean Michael Heithaus

College of Arts, Sciences and Education

This thesis, written by Theresa Kelly Brown, and entitled Taking Apart the Time Machine: Investigating Space-for-Time Substitution Modeling in the Florida Everglades, having been approved in respect to style and intellectual content, is referred to you for judgment.

We have read this thesis and recommend that it be approved.

Jennifer Richards

Sarah Eddy

Leonard Pearlstine

Joel C. Trexler, Major Professor

Date of Defense: December 4, 2019

The thesis of Theresa Kelly Brown is approved.

Dean Michael Heithaus

College of Arts, Sciences and Education

Andrés G. Gil

Vice President for Research and Economic Development and Dean of the University Graduate School

Florida International University, 2019 


\section{DEDICATION}

This thesis is dedicated to my wife, Rebecca, and my daughter, Teagan. Thank you both for accompanying me on this grand adventure. I hope that Teagan keeps looking at the natural world with awe and wonder for the rest of her days. 


\section{ACKNOWLEDGMENTS}

I would like to thank all the technicians and graduate students in the Trexler lab. Without your hard work my research would not have been possible. Many people have worked with the projects on which my research is based during the past five years. Lab managers Bree Zenone, Chase Rakowski, and Sofia Burgos have fixed computer issues, provided many hours of programming assistance, and enabled me to continue my work when I left Miami. I am very grateful for Somers Smott's contribution to this project. She worked with me on the CERP data and helped me see things from a new perspective when I couldn't find a way to move forward. I am also thankful for Daniel Chomin-Virden, who always had time to help to me talk through ideas and always had something encouraging to say when I needed it most. Finally, I am grateful for the guidance and assistance of my committee members and my advisor, Dr. Joel Trexler. This project was funded through the Everglades National Park Cooperative Research Agreement and the Florida Coastal Everglades Long-Term Ecological Research Program. 


\section{ABSTRACT OF THE THESIS \\ TAKING APART THE TIME MACHINE: \\ INVESTIGATING SPACE-FOR-TIME SUBSTITUTION MODELING IN THE FLORIDA EVERGLADES \\ by}

\section{Theresa Kelly Brown}

Florida International University, 2019

Miami, Florida

Professor Joel C. Trexler, Major Professor

Space-for-Time substitution modeling has been used with increasing frequency to identify functional relationships between environmental drivers and ecological responses. I investigated the use of space-for-time substitution as a null model and beta diversity as a validity test for this null model in the Greater Everglades aquatic metacommunity. I began by conducting a literature review and analysis to investigate the suitability of the spacefor-time substitution method as a null model. I then analyzed beta diversity of the Greater Everglades aquatic metacommunity through a sums-of-squares approach. Finally, I tested for correlation between the beta diversity analysis and the space-for-time models. Results indicate that while beta diversity is correlated with space-for-time model success for some species, the relationship is not consistently significant and therefore not suited for validity testing. Space-for-Time substitution is suitable for use as a null model but cannot be used reliably in predictive models for management purposes. 


\section{TABLE OF CONTENTS}

CHAPTER

PAGE

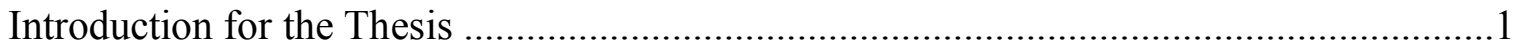

Space-for-Time Substitution Literature Review ....................................................

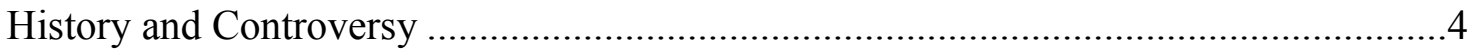

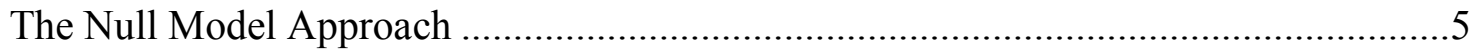

Testing Space-for-Time Substitutions.......................................................................

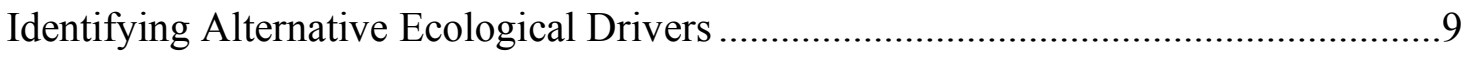

When the Null Model is Rejected ........................................................................ 11

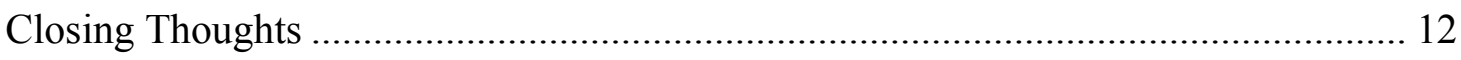

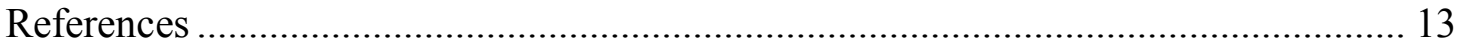

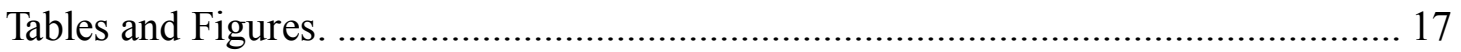

Testing Space-for-Time Substitution in the Everglades ...........................................25

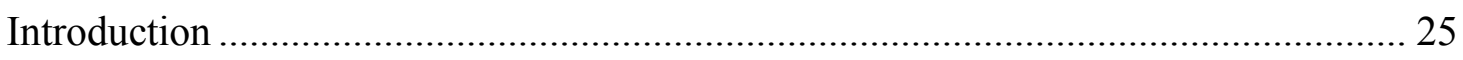

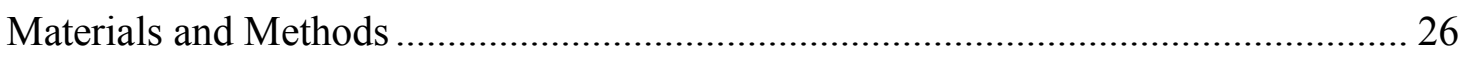

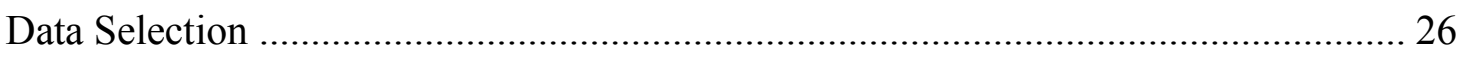

Quantifying Metacommunity Dynamics through Diversity Analysis....................... 29

Creating Space-for-Time Substitution Models ........................................................ 30

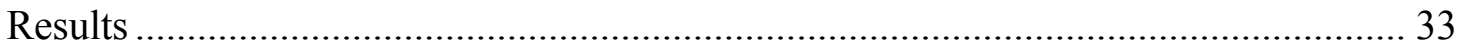

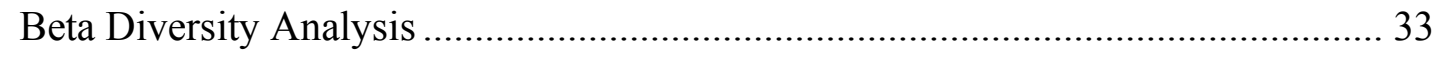

Space-for-Time Substitution Models.............................................................. 35

Space-for-Time Substitution and Beta Diversity Correlation ............................... 35

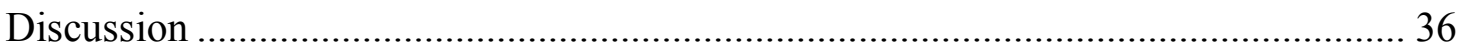

Beta Diversity in the Greater Everglades Aquatic Metacommunity ....................... 36

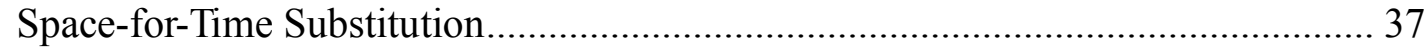

Correlation between Space-for-Time Substitution and Beta Diversity .................... 39

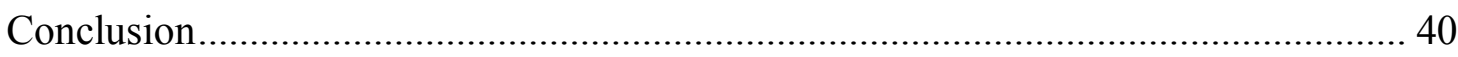

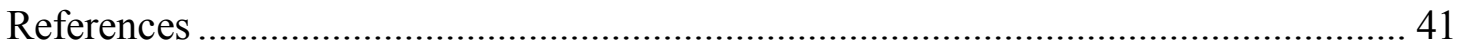

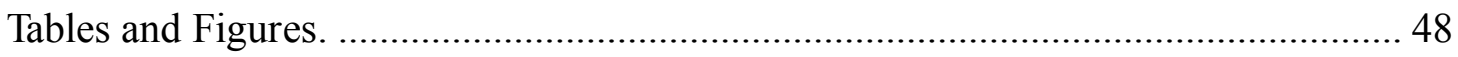

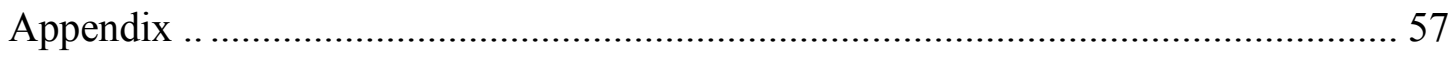




\section{LIST OF TABLES}

\section{SPACE-FOR-TIME LITERATURE REVIEW}

TABLE

PAGE

Table 1. Highly cited studies that use the space-for-time substitution method.

Complete citations can be found in reference section....

Table 2. Studies that test space-for-time substitution validity. Complete citations

can be found in reference section .... 18

\section{TESTING SPACE-FOR-TIME SUBSTITUTION IN THE EVERGLADES}

TABLE

PAGE

Table 1. Species with high Contribution to Beta Diversity (SCBD) ................44

Table 2. Proportion of models where spatial data could be successfully substituted

for temporal data by region and species .46 


\section{LIST OF FIGURES}

\section{SPACE-FOR-TIME LITERATURE REVIEW}

FIGURE

PAGE

Figure 1. Number of articles in the Web of Science Core collection containing the keywords 'space-for-time substitution' or 'chronosequence' from $1980-2018 \ldots \ldots \ldots .22$

Figure 2. Percentage of articles from figure 1 in fields other than agriculture, plant science, and soil science.

\section{TESTING SPACE-FOR-TIME SUBSTITUTION IN THE EVERGLADES}

FIGURE

PAGE

Figure 1. Map of MDW and CERP sampling areas............................47

Figure 2. Illustration of the sums-of-squares beta diversity analysis (left) and definitions of variables derived from the analysis (right)

Figure 3. A. Proportion of study sites where the marsh surface dried within the 365 days before sampling plotted by year. B. Maps illustrating PSUs that dried in 365 before sampling and PSUs that did not dry (Trexler 2016) ...................... 50

Figure 4. Greater Everglades Aquatic Metacommunity Species Distribution........... 51

Figure 5. BDtotal for CERP monitoring area, $2005-2016 \ldots \ldots \ldots \ldots \ldots \ldots \ldots \ldots \ldots \ldots$

Figure 6. Relationship between species biomass and SCBD $\ldots \ldots \ldots \ldots \ldots \ldots \ldots \ldots . \ldots \ldots$

Figure 7. Model species contribution to beta diversity in the Shark River Slough (top) and Water Conservation Area 3A (bottom) region of CERP from $2005-2016$

Figure 8. Proportion of successful space-for-time substitution models by year

Figure 9. Results of Pearson's correlation coefficient test by model species and region 


\section{Introduction for the Thesis}

Simulation models have become important tools for conservation management as global climate change pushes the field of ecology toward a more predictive science (Urban et al. 2012, Thuiller et al. 2013). Conservation managers need reliable ecological modeling tools to quantify and project the effects of changes on vulnerable species at local and regional scales. Incorporation of spatial and temporal variables allows for the creation of predictive models that will more closely reflect the dynamics of natural metacommunities. Parameterizing such models is data-intensive and often is challenged by the limits of available information. The lack of data often requires ecologists to employ data gathered at temporal or spatial scales that do not match the model applications, which can only be accomplished by making assumptions and employing short-cuts. Space-for-time substitution is one such assumption. For example, in a largescale review of several types of climate change modeling, researchers found that spacefor-time-substitution models consistently overestimated the effects of warming on plant communities (Elmendorf et al 2015). These models assumed that spatial and temporal temperature gradients were interchangeable. The study found that this assumption was false because warming from climate change progressed at a rapid pace, whereas the spatial temperature gradient had stabilized over a long period.

Space-for-time substitution modeling, or chronosequencing, uses spatial replicates in place of temporal replicates to establish functional relationships between biotic parameters and abiotic drivers. This technique can be used to create forecast models when long-term data are not available (Johnson and Miyanishi 2008). Space-for-time 
substitution has been used extensively in climate forecasting (Mbogga et al. 2010) and in species succession models (Billings 1938). However, recent studies have shown that space-for-time substitution models often do not accurately predict actual developmental trends (Fukami and Wardle 2005, Johnson and Miyanishi 2008, Walker et al 2010). Johnson and Miyanishi (2008) reviewed resampling studies of the Billings' old-field succession model and several other classic space-for-time substitution models. They found that none of the classic space-for-time substitutions showed a good fit for the longterm data and concluded that the method was not suitable for use in successional studies because the assumption that each site in the chronosequence followed the same developmental track regardless of differences in abiotic and biotic conditions was incorrect. A recent study in the Florida Everglades showed some promise in predicting the distribution of a single species using space-for-time substitution, but only in areas where connectivity among sites was high (Banet and Trexler 2013). Despite problems with this technique, space-for-time substitution continues to be widely used in forecast modeling because of the low availability of long time-series data.

Presence of high levels of habitat heterogeneity is cited as an ecological driver correlated with reliability of space-for-time substitution models (Barcena et al 2014, He et al 2002). Beta diversity analysis provides a means to quantify heterogeneous distribution of species within a variable landscape. In the GE region, abundance of some aquatic metacommunity species shows a correlation with days since the site was last dry. Species that are more affected by hydrological cycles will be less evenly distributed throughout the region and have a higher contribution to beta diversity. 
Previous studies have validated space-for-time substitution by comparing chronosequence results to long-term data observations (Banet and Trexler 2013). However, this method requires access to long-term data, which is not available in many areas where space-for-time substitution is used. Beta diversity analysis is attractive as a test of validity because, in contrast to other methods that have been previously used to test the predictive power of space-for-time substitutions, it does not require long-term data. A diversity analysis is conducted on a snapshot of data that covers a spatially extensive area.

In this thesis, I evaluated space-for-time substitution in a diverse aquatic metacommunity. The goal of this project was to demonstrate the use of space-for-time substitution modeling as a null hypothesis and to test for correlation between beta diversity and space-for-time substitutability. 


\section{Space-for-Time Substitution Literature Review}

\section{History and Controversy}

Space-for- time substitution exists at the intersection of controversy and ubiquity in modern ecology. The method has been widely used in studies of agriculture and forest succession for more than a century. Classic chronosequences like Billings' 1938 old-field succession model still appear in introductory ecology textbooks. The number of studies using space-for-time substitution has risen sharply over the past four decades (Figure 1). Using a Web of Science search, I found 4,128 articles published 1980-2018 that use the space-for-time substitution method. The number of articles that include either 'space-fortime substitution' or 'chronosequence' as a keyword has risen from 4 in 1980 to 383 in 2018. The scope of the method has also expanded. Space-for-time substitution was originally developed for use in plant succession research; for many years the method was used almost exclusively in the fields of agriculture, plant, and soil science. However, space-for-time substitution is now used in a wide range of studies (Figure 2). The Web of Science keyword search revealed that studies in the past decade have included fields such as geology, physics, medicine, and reproductive ecology.

Studies have shown, however, that Billings' model and other chronosequences to be unreliable as predictive models (Fukami and Wardle 2005, Johnson and Miyanishi 2008, Walker et al. 2010). Johnson and Miyanishi reviewed resampling studies of the Billings' old-field succession model and several other classic space-for-time substitution models. They found that none of the classic space-for-time substitutions showed a good fit for the long-term data and concluded that the method was not suitable for use in 
successional studies. The assumption that each site in the chronosequence followed the same developmental track regardless of differences in abiotic and biotic conditions was unsupported by the data.

Researchers who have made extensive use of space-for-time substitution in the past have also grown critical of the method. In a 2018 commentary, Wardle and Ghani critiqued their earlier work on the Franz-Josef Glacier chronosequence, a New Zealand sequence spanning more than 120,000 years (Wardle and Ghaini 2018). They concluded that the sites in this region could not be satisfactorily arranged along any unidimensional axis because of differences in disturbance regimes among the sites.

\section{The Null Model Approach}

Despite the controversy, use of the space-for-time substitution method has not slowed.

In the past 10 years, Web of Science has identified 10 space-for-time substitution studies as highly cited in their field (table 1). Of these 10 papers, three used space-for-time substitution modeling as one method in a multi-part analysis. The remaining seven studies relied solely on the chronosequence model for analysis. Three of these highly cited articles based their models on previously constructed chronosequences, including the Franz-Josef Glacier sequence.

We analyzed 40 studies that directly test the validity of the space-for-time substitution method (table 2). Ten studies supported the use of space-for-time substitution, while twelve found no support for the continued use of the method. The largest group, including 18 of the 40 studies analyzed, showed conditional support for space-for-time substitution. These studies discussed limited parameters under which the 
method might be appropriate. For example, Wardle and Ghani (2018) recommend that $q \mathrm{CO}_{2}$ chronosequences not encompass both stressed and disturbed ecosystems, as these very different ecosystem types may show similar $q \mathrm{CO}_{2}$ values. Walker et al (2010) lay out a number of guidelines for using space-for-time substitution in ecological succession studies. They recommend that the method be reserved for communities with low biodiversity, rapid species turnover, and low disturbance frequency.

These recommendations and cautions are well researched and helpful in their respective fields. However, the space-for-time substitution method is being used in an expanding range of fields and locations. Chronosequences are relatively simple to create and can offer valuable insight into the developmental track of many study systems. If these models are to be useful tools, they must be reliable in any context.

We propose that the space-for- time substitution method be viewed as a null model. Under this approach, the null hypothesis states that spatial replicates can be substituted for temporal replicates because the directional change through time is the same at all sites. As with any null model, this hypothesis must be tested before using the substitution model to make predictions. If the null model is rejected, then spatial replicates cannot be substituted for temporal replicates because sites vary in temporal development. In this case, significant spatially heterogeneous ecological drivers can be identified. Reliable models for the study system would need to incorporate these drivers.

Below, we have identified methods that can be used to test this null model. As several of these methods do not require long-term data, use of chronosequences as a null model is possible in a wide range of studies. We also recognize four categories of common ecological drivers that can direct the creation of alternative hypotheses when a 
chronosequence is rejected, and we identify a priori systems where unscrutinized spacefor-time substitution is ill advised.

\section{Testing Space-for-Time Substitutions}

The simplest method of testing the validity of the space-for-time substitution null model in a given environment is to resample a previously constructed chronosequence. Of the 40 studies analyzed, nine used the resampling method to test space-for-time substitution models. When testing space-for-time substitution by resampling it is important to match sampling methods and locations as closely as possible with the original study. Incomplete resampling efforts could result in failing to reject the null space-for-time model when change in the response variable through time is heterogeneous within the sampling area (Barcena et al. 2014). Resampling can clearly show the predictive power of the chronosequence being studied, however previously constructed chronosequences are only useful as null models if further studies are being conducted involving the same response variables, sampling methods, and location as the original chronosequence.

When long-term data are available in the study area, but no previously constructed chronosequence is available that closely matches the current study parameters, the validity of the space-for-time substitution null model can be tested by using older data to construct a chronosequence and then comparing that chronosequence to current data. Creating multiple chronosequences from available long-term data can lead to higher power tests of the space-for-time substitution null model.

In cases where long-term data have not been collected in the study area, proxies can be found using other methods. For extremely large-scale studies, paleo or 
archeological data records can be used to create chronosequences that can then be tested against current data. This method has been used successfully with both plant and animal studies, for example fossilized pollen records were used to predict current species distributions at the continental level (Pearman et al. 2008), and bony fish fossils were used to create a chronosequence predicting Hawaiian parrot fish distribution (Longenecker et al. 2014).

In studies of plant succession, the stable carbon isotopic composition $\left(\delta_{13} \mathrm{C}\right)$ of soil organic carbon has been successfully used to infer temporal patterns of vegetation change in order to validate previously constructed chronosequences (Bai et al. 2012). Tree, soil, and ice cores can also provide proxies for temporal data. Long-term data can also be proxied by creating chronological models that do not rely on space-for-time substitutions. Models created using the Before and After Controlled Impact (BACI) method are appropriate in studies of point disturbance response. BACI models were shown to be superior to space-for-time substitutions in predicting the response of Dung Beetle populations to logging of varying intensities (Franca et al. 2016). For highly variable systems, chronosequences can be compared to models created using timestratified replicated sampling over several seasons (Kappes et al. 2010).

When long-term data are not available and cannot be proxied through other methods, tests of the space-for-time substitution null model can be accomplished through experiments that directly examine changes in the response variable. Laboratory, mesocosm, or in situ experiments can be used to find the rate of change in a response variable that can then be compared to the predicted rate of change seen in the chronosequence. Elmendorf et al. (2015) showed that a chronosequence created using 
temperature as a gradient factor consistently overestimated plant community response when compared to in situ experimental warming. Laboratory experiments are often appropriate for comparison to chronosequences that examine micro processes. For example, pooled results of laboratory warming experiments on marine microbial food webs were shown to predict a stronger warming effect than that predicted by space-fortime substitution (Sarmento et al. 2010). Chronosequences can also be tested through comparison to alternative model types that do not rely directly on temporal trends.

Clemmensen et al. (2015) were able to validate a boreal forest carbon sequestration chronosequence by creating a second model based on island size. They showed that the space-for-time model more closely reflected the data, despite differences in disturbance regime between sites used to construct the chronosequence. Thirteen studies used alternative models or experiments to validate space-for-time substitutions.

\section{Identifying Alternative Ecological Drivers}

If the null model created through space-for-time substitution is rejected, the next step is to identify ecological drivers that can explain differences in chronosequence site development. In reviewing studies that tested the validity of space-for-time substitutions in a wide range of systems, three broad categories of ecological drivers were cited as creating significant differences in spatial and temporal variability: spatial heterogeneity, disturbance events, and confounding variables.

Even when the heterogeneous factors are not directly linked to the response variable in a study, spatial heterogeneity leads to site-specific conditions that can cause a mismatch between temporal and spatial variability. For example, a resampling validation of 15 chronosequences that modeled changes in soil organic carbon in Norwegian oak 
and spruce woodlands rejected only one of the models (Barcena et al. 2014). Upon examination, the rejected chronosequence was shown to have been created in a woodland with high spatial heterogeneity, while the 14 other woodland sites were more homogeneous. Spatial connectivity is a related factor that can affect variability in a system. Organisms that are isolated within a patchy landscape with low spatial connectivity will have more heterogeneous populations (Banet and Trexler 2013). Spatial heterogeneity was cited as a limiting factor for space-for-time substitution in 11 of the 40 studies analyzed.

Temporal projections necessarily rely on the assumption that environmental factors will persist within a given range of variability for the duration of the projected period. When disturbance events cause major changes in an environment, the trajectory or rate of change in a response variable predicted by a chronosequence will show less correlation with actual data. Disturbance events were cited as a limiting factor in six studies. The probability that a disturbance event will result in the rejection of a space-fortime substitution null model is related to both the intensity and size of the disturbance, and to the spatiotemporal scale of the chronosequence. A hurricane may significantly change the course of island vegetation succession over a decade, but the same storm would have little effect on the predictive power of a century-long chronosequence on a continental scale. Disturbance events that result in chronosequence rejection can include both pulse events, like hurricanes (Chai et al. 2012) and press events, such as land-use changes (Bonthoux et al. 2013).

Variables other than the chronosequence response variable that have differing rates of spatiotemporal change can affect the performance of space-for-time substitution 
in complex environments. These confounding variables were cited as limiting factors in 12 studies. In a study of birch flowering times across an urban gradient, variation in soil conditions, pollution levels, nutrient availability, and water supply were indicated as possible confounding factors causing poor fit with an air temperature gradient chronosequence (Jochner et al 2013). It is also possible for the response variable in a chronosequence to lag in relation to other predictor variables. For example, a chronosequence modeling bluefin killifish (Lucania goodei) density in relation to water depth produced a poor fit due to the temporal lag between rising water depth and increase in population size (Banet and Trexler 2013).

\section{When the Null Model is Rejected}

If the space-for-time substitution null hypothesis is rejected, spatially heterogeneous ecological drivers must be identified. These drivers can be accounted for in one of two ways. If the ecological drivers affecting the space-time model fit can be isolated to a small number of sites, as in the case of small-scale disturbance events or isolated geophysical differences, then those sites can simply be dropped from the chronosequence and the null hypothesis tested again. If the ecological drivers are present in differing levels at all or most sites, such as site-specific hydrological differences or pollution gradients, then they can be incorporated into the model as additional gradient factors.

We need to accept that space-for-time substitution may be ill-advised in some circumstances. In fact, rejecting it informs us about the fundamental dynamics of the system under study. The use of space-for-time substitution is only appropriate for populations, communities, or ecosystems fluctuating within a domain of feedbacks 
leading to predicable responses to environmental fluctuation (Walker et al. 2010, Wardle and Ghani 2018). These differences need not be as dramatic as shifts to alternative stable states. We found that lumping population dynamics of a fish species in Everglades regions that experienced different histories of hydrological fluctuation and access to drought refuges increased the range of hydrological conditions in our spatial model but decreased its consistency with temporal models (Banet and Trexler 2013). By expanding the spatial domain of data, we identified regions with different dynamical controls.

\section{Closing Thoughts}

Because of the assumption that all sites within a chronosequence develop at equal rates through time, the space-for-time substitution method as it has been historically implemented is useful only to show generic trends, as when the mechanism of succession is being explained in an introductory ecology text. Models created using this method have frequently been found to be unreliable in predicting real-world long-term data. In order to make space-for-time substitution useful for implementation outside of the theoretical realm, the basic chronosequence must be viewed as a null model. This null model can then be tested and if rejected it can be updated until a satisfactory model is achieved. 


\section{References}

Bai, E. et al. (2012) Spatial patterns of soil delta C-13 reveal grassland-to-woodland successional processes. Org. Geochem. 42, 1512-1518

Banet, A. I. and Trexler, J. C. (2013) Space-for-Time Substitution Works in Everglades Ecological Forecasting Models. PLoS One 8, e81025

Barcena, T. G. et al. (2014) Afforestation effects on SOC in former cropland: oak and spruce chronosequences resampled after 13 years. Glob. Change Biol. 20, 2938-2952

Blois, J. L. et al. (2013) Space can substitute for time in predicting climate-change effects on biodiversity. Proc. Natl. Acad. Sci. U. S. A. 110, 9374-9379

Bonthoux, S. et al. (2013) Contrasting spatial and temporal responses of bird communities to landscape changes. Oecologia 172, 563-574

Chai, S. L. et al. (2012) Evaluation of Forest Recovery over Time and Space Using Permanent Plots Monitored over 30 Years in a Jamaican Montane Rain Forest. PLoS One 7, e48859

Chaideftou, E., et al. (2012) How does plant species composition change from year to year? A case study from the herbaceous layer of a submediterranean oak woodland. Community Ecol. 13, 88-96

Clemmensen, K. E. et al (2013) Roots and Associated Fungi Drive Long-Term Carbon Sequestration in Boreal Forest. Science. 339, 1615-1618

Clemmensen, K. E. et al. (2015) Carbon sequestration is related to mycorrhizal fungal community shifts during long-term succession in boreal forests. New Phytologist. $205,1525-1536$

De Lombaerde, E. et al. (2018) Responses of competitive understorey species to spatial environmental gradients inaccurately explain temporal changes. Basic and Applied Ecology. 30, 52-64

Derderian, D. P. et al. Bark beetle effects on a seven-century chronosequence of Engelmann spruce and subalpine fir in Colorado, USA. For. Ecol. Manage. 361, 154162

Dini-Andreote, F. et al. (2015) Disentangling mechanisms that mediate the balance between stochastic and deterministic processes in microbial succession. PNAS. 112, E1326-E1332 
Dobrowski, S. Z. et al. (2011) Modeling plant ranges over 75 years of climate change in California, USA: temporal transferability and species traits. Ecol. Monogr. 81, $241-257$

Eby, S. et al. (2017) Alternative stable states and spatial indicators of critical slowing down along a spatial gradient in a savanna ecosystem. Plant Science. 26, 638-649

Elmendorf, S. C. et al. (2015) Experiment, monitoring, and gradient methods used to infer climate change effects on plant communities yield consistent patterns. Proc.

Natl. Acad. Sci. U. S. A. 112, 448-452

França, F. et al. (2016) Do space-for-time assessments underestimate the impacts of logging on tropical biodiversity? An Amazonian case study using dung beetles. J Appl Ecol 53, 1098-1105

Fukami, T. and Wardle, D. (2005) Long-term ecological dynamics: reciprocal insights from natural and anthropogenic gradients. Proceedings of the Royal Society B: Biological Sciences 272, 2105-2115

Goulden, M. L. et al. (2011) Patterns of NPP, GPP, respiration, and NEP during boreal forest succession. Global Change Biology. 17, 855-871

Hammond, M. P. and Kolasa, J. (2014) Spatial Variation as a Tool for Inferring Temporal Variation and Diagnosing Types of Mechanisms in Ecosystems. PLoS One 9, e89245

Isaac, N. J. B. et al. (2010) Butterfly abundance in a warming climate: patterns in space and time are not congruent. J Insect Conserv 15, 233-240

Jochner, S. et al. (2013) Can spatial data substitute temporal data in phenological modelling? A survey using birch flowering. Tree Physiol. 33, 1256-1268

Johnson, E. A. and Miyanishi, K. (2008) Testing the assumptions of chronosequences in succession. Ecol. Lett. 11, 419-431

Kappes, H. et al. (2010) High spatial variability biases the space-for-time approach in environmental monitoring. Ecological Indicators 10, 1202-1205

Kharouba, H. M. et al. (2009) Historically calibrated predictions of butterfly species' range shift using global change as a pseudo-experiment. Ecology 90, 2213-2222

La Sorte, F. A. et al. (2009) Disparities between observed and predicted impacts of climate change on winter bird assemblages. Proc. R. Soc. B-Biol. Sci. 276, 31673174

Li, S. et al. (2015) Species colonisation, not competitive exclusion, drives community overdispersion over long-term succession. Ecol. Lett. 18, 964-973 
Li, W. K. W. et al. (2013) Space-for-time substitution in predicting the state of picoplankton and nanoplankton in a changing Arctic Ocean. J. Geophys. Res.-Oceans $118,5750-5759$

Li, Y. et al. (2017) Linking soil fungal community structure and function to soil organic carbon chemical composition in intensively managed subtropical bamboo forests. Soil Biology \& Biochemistry. 107, 19-31

Liu, G. and Schwartz, F. W. (2012) Climate-driven variability in lake and wetland distribution across the Prairie Pothole Region: From modern observations to longterm reconstructions with space-for-time substitution. Water Resour. Res. 48, W08526

Longenecker, K. et al. (2014) Archaeological Evidence of Validity of Fish Populations on Unexploited Reefs as Proxy Targets for Modern Populations. Conserv. Biol. 28, 1322-1330

Maher, K. (2010) The dependence of chemical weathering rates on fluid residence time. Earth and Planetary Science Letters. 294, 101-110

Martinez-Garcia, L. B. et al. (2014) Host identity is a dominant driver of mycorrhizal fungal community composition during ecosystem development. New Phytologist. 205, 1565-1576

Miao, R. et al. (2018) Accuracy of space-for-time substitution for vegetation state prediction following shrub restoration. Journal of Plant Ecology. 11, 208-217

Micallef, A. et al. (2014) Space-for-time substitution and the evolution of a submarine canyon-channel system in a passive progradational margin.

Geomorphology 221, 34-50

Mimet, A. et al. (2016) A Holistic Landscape Description Reveals That Landscape Configuration Changes More over Time than Composition: Implications for Landscape Ecology Studies. PLoS One 11, e0150111

Pearman, P. B. et al. (2008) Prediction of plant species distributions across six millennia. Ecol. Lett. 11, 357-369

Racz, I. A. et al. (2013) Early changes of orthopteran assemblages after grassland restoration: a comparison of space-for-time substitution versus repeated measures monitoring. Biodivers. Conserv. 22, 2321-2335

Richardson, M. and Stolt, M. (2013) Measuring Soil Organic Carbon Sequestration in Aggrading Temperate Forests. Soil Science Society of America Journal 77, 2164

Rolo, V. et al. (2016) Validating space-for-time substitution in a new-growth coastal dune forest. Appl. Veg. Sci. 19, 235-243 
Sarmento, H. et al. (2010) Warming effects on marine microbial food web processes: how far can we go when it comes to predictions? Philosophical Transactions of the Royal Society of London B: Biological Sciences 365, 2137-2149

Schrama, M. et al. (2012) Ecosystem assembly rules: the interplay of green and brown webs during salt marsh succession. Ecology 93, 2353-2364

Solomon, Z. et al (2011) Modeling plant ranges over 75 years of climate change in California, USA: temporal transferability and species traits. Ecological Monographs $81,241-257$

Temme, A. J. A. M. et al. (2015) Time development of soils in mountain landscapesdivergence and convergence of properties with age. Journal of Soils and Sediments. $15,1373-1382$

Thomaz, S. M. et al. (2012) Using space-for-time substitution and time sequence approaches in invasion ecology. Freshw. Biol. 57, 2401-2410

Walker, L. R. et al. (2010) The use of chronosequences in studies of ecological succession and soil development. Journal of Ecology 98, 725-736

Wardle, D. and Ghani, A. (2018) A tale of two theories, a chronosequence and a bioindicator of soil quality. Soil Biology and Biochemistry 121, A3-A7

Williams, M. W. et al. (2011) Stream Water Chemistry along an Elevational Gradient from the Continental Divide to the Foothills of the Rocky Mountains. Vadose Zone J. $10,900-914$

Zemunik, G. et al. (2015) Diversity of plant nutrient-acquisition strategies increases during long-term ecosystem development. Nature Plants. 5, 1-4

Zhang, C. et al. (2016) Soil bacterial community dynamics reflect changes in plant community and soil properties during the secondary succession of abandoned farmland in the Loess Plateau. Soil Biology \& Biochemistry. 97, 40-49

Zhang, H. et al. (2018) Relationship between soil nutrient properties and biological activities along a restoration chronosequence of Pinus tabulaeformisplantation forests in the Ziwuling Mountains, China. CATENA. 161, 85-95

Zhu, D. et al. (2013) Temporal and spatial trends of residential energy consumption and air pollutant emissions in China. Appl. Energy 106, 17-24 
Table 1. Highly cited studies that use the space-for-time substitution method. Complete citations can be found in reference section

\begin{tabular}{lccc}
\multicolumn{1}{c}{ Authors } & Year & $\begin{array}{c}\text { Validity } \\
\text { Test }\end{array}$ & $\begin{array}{c}\text { Based on Previous } \\
\text { Chronosequence }\end{array}$ \\
\hline Clemmensen et al. & 2015 & X & - \\
Clemmensen et al. & 2013 & X & - \\
Dini-Andreote et al. & 2015 & X & X \\
Goulden et al. & 2011 & - & - \\
Maher, K & 2010 & - & - \\
Li et al. & 2017 & - & - \\
Martinez-Garcia et al. & 2014 & - & X \\
Zemunik et al. & 2015 & - & X \\
Zhang et al. & 2018 & - & - \\
Zhang et al. & 2016 & - & -
\end{tabular}


Table 2. Studies that test space-for-time substitution validity. Complete citations can be found in reference section.

\begin{tabular}{|c|c|c|c|c|}
\hline Authors & Year & Testing method & Findings & Ecological Drivers \\
\hline Bai, E. et al. & 2012 & Other Model & supportive & none \\
\hline Banet, A. I. and Trexler, J C. & 2013 & Long-Term Data & conditional & spatial heterogeneity, confounding variables \\
\hline Barcena, T. G. et al. & 2014 & Resampling & conditional & spatial heterogeneity \\
\hline Blois, J. L. et al. & 2013 & Long-Term Data & conditional & spatial heterogeneity \\
\hline Bonthoux, S. et al. & 2013 & Resampling & unsupportive & disturbance events \\
\hline Chai, S. et al. & 2012 & Resampling & conditional & disturbance events \\
\hline Chaideftou, E. et al. & 2012 & Resampling & supportive & none \\
\hline Clemmensen, K. E. et al. & 2015 & Other Model & supportive & none \\
\hline De Lombaerde, E. et al. & 2018 & Resampling & conditional & confounding variables \\
\hline Derderian, D. P. et al. & 2016 & Resampling & unsupportive & disturbance events \\
\hline Dobrowski, S. Z. et al & 2011 & Long-Term Data & conditional & confounding variables \\
\hline Dobrowski, S. Z. et al. & 2011 & Long-Term Data & conditional & confounding variables \\
\hline
\end{tabular}




\begin{tabular}{|c|c|c|c|c|}
\hline Eby, S. et al. & $\begin{array}{l}201 \\
7\end{array}$ & Other Model & supportive & none \\
\hline $\begin{array}{l}\text { Elmendorf, S. C. et } \\
\text { al. }\end{array}$ & $\begin{array}{l}201 \\
5\end{array}$ & Other Model & conditional & confounding variables \\
\hline França, F. et al. & $\begin{array}{ll}2 & 01 \\
6\end{array}$ & Other Model & unsupportive & none \\
\hline Hammond, M. P. and Kolasa, J. & $\begin{array}{l}201 \\
4\end{array}$ & Other Model & conditional & spatial heterogeneity \\
\hline Isaac, N. J. B. et al. & 2011 & Other Model & unsupportive & confounding variable \\
\hline Jochner, S. et al. & $\begin{array}{l}201 \\
3\end{array}$ & Long-Term Data & unsupportive & spatial heterogeneity, confounding variables \\
\hline \multirow[t]{2}{*}{$\begin{array}{l}\text { Johnson, E. A. and Miyanishi, } \\
\text { K. Kappes, H. et al. }\end{array}$} & $\begin{array}{l}200 \\
8\end{array}$ & Resampling & unsupportive & confounding variables, spatial heterogeneity \\
\hline & $\begin{array}{l}201 \\
0\end{array}$ & Other Model & unsupportive & spatial heterogeneity \\
\hline Kharouba, H. R. et al. & $\begin{array}{l}200 \\
9\end{array}$ & Long Term Data & conditional & confounding variables \\
\hline La Sorte, F. A. et al. & $\begin{array}{l}200 \\
9\end{array}$ & Long-Term Data & conditional & spatial heterogeneity \\
\hline $\mathrm{Li}$, S. et al. & $\begin{array}{l}201 \\
5\end{array}$ & Long-Term Data & unsupportive & none \\
\hline Li, W. K. W. et al. & $\begin{array}{l}201 \\
3\end{array}$ & Long-Term Data & conditional & spatial heterogeneity \\
\hline $\begin{array}{l}\text { Liu, G. and Schwartz, F. } \\
\text { W. }\end{array}$ & $\begin{array}{l}201 \\
2\end{array}$ & Long-Term Data & supportive & none \\
\hline
\end{tabular}


Longenecker, K. et al.

Miao, R. et al.

Micallef, A. et al.

Mimet, A. et al.

Pearman et al.

Racz, I. A. et al.

Richardson, M. and Stolt, M.

Rolo, V. et al.

Sarmento, Hugo et al.

Schrama, M. et al.

Temme, A. J. A. M. et al.

Thomaz, S. M. et al.

Wardle, D. and Ghani, A.
2014 Long-Term Data Proxy

supportive

2018 Long-term data conditional

2014 Other Model

supportive

2016

Long-Term Data

unsupportive

2008 Long-Term Data Proxy

conditional

2013

Long-Term Data

unsupportive

2013

Other Model

unsupportive

supportive

unsupportive

2012

2015

2012

2018
Resampling

Other Model

Long-Term Data

Resampling

Long-Term Data

Other Model supportive

conditional

conditional

conditional none

disturbance events

none

spatial heterogeneity

confounding variables

none

none

none

confounding variables

none

disturbance events

confounding variables

disturbance events 
Williams, M. W. et al.

Zhu, D. et al.
2011

2013

\section{Other Model}

Long-Term Data conditional

none

supportive

none 


\section{Figure Legends}

Figure 1. Number of articles in the Web of Science Core collection containing the keywords 'space-for-time substitution' or 'chronosequence' from 1980 - 2018

Figure 2. Percentage of articles from figure 1 in fields other than agriculture, plant science, and soil science 
Figure 1.

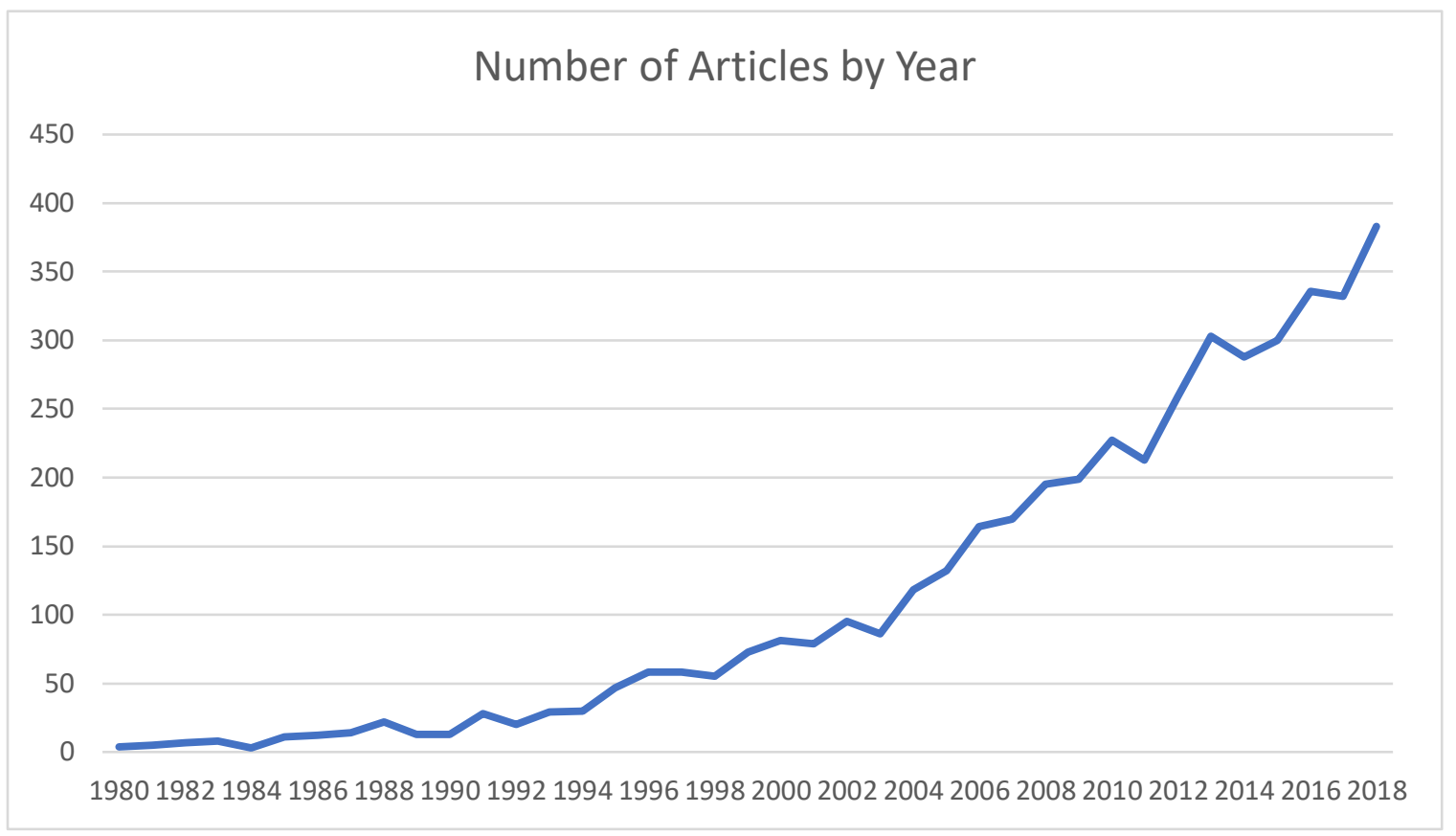


Figure 2.

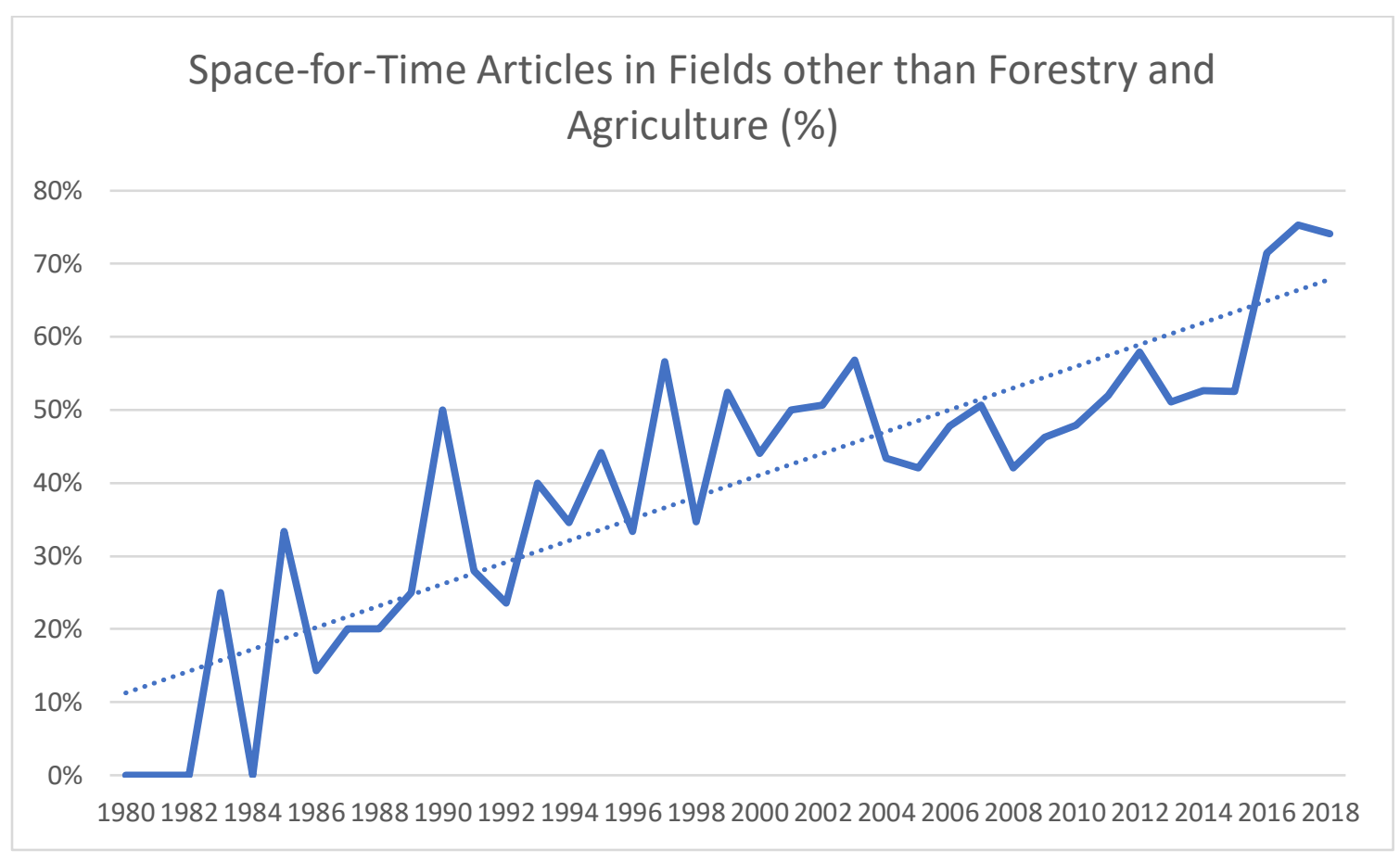




\section{Testing Space-for-Time Substitution in the Everglades}

\section{Introduction}

Climate change, anthropogenic changes to the hydrologic cycle, and nutrient addition are altering the Florida Everglades ecosystem at a rapid pace (Sklar et al. 2005; Pearlstine et al. 2010). Management and restoration efforts require reliable projection models. These models must show functional relationships between the environmental factors and ecosystem performance measures. Space-for-time substitution could be a useful tool to identify these relationships, but only if it can be validated through a null model assessment of its validity in this region (Elmendorf et al 2015, Chapter 1 this thesis). Beta diversity, which measures the change in species composition between sites, can be used as an indicator of species dispersal rates. High beta diversity has been suggested as an indicator that a system may not be suitable for space-for-time substitution modeling (Banet and Trexler 2013, Kappes et al 2010), but this correlation has not been tested directly. This study had two main objectives. First, to test a multiple species null model of space-for-time substitution in the Florida Everglades using a broad spatial and temporal scale. And second, to test for a correlation between space-for-time model reliability and individual species' contributions to beta diversity.

The Florida Everglades is a seasonally pulsed wetland with abundant rainfall from May through October and a dry season from November through April. Many sites experience periodic drying events that vary in duration and frequency due to small differences in elevation and hydrological cycles. Aquatic animals have proven to be useful performance measures of Everglades ecosystem health because of their sensitivity 
to hydrological variation and relatively rapid response time (Trexler and Goss 2009). Variation in interannual and intra-annual rainfall coupled with variability in landscape connectivity affects dispersal of aquatic metacommunity species in this environment (Hoch et al. 2015; Parkos and Trexler 2014).

Banet and Trexler (2013) found conditional support for a chronosequence modeling distribution of Bluefin Killifish (Lucania goodei) in relation to days since a drying event. Models created in that study were least reliable in areas with high landscape heterogeneity and lower species dispersal rates. I explored those data further to determine if community metrics related to beta diversity can be used to identify taxa with space-fortime substitutability. I analyzed beta diversity using a sums-of-squares approach (Legendre and Caceres 2013) that measured both total beta diversity and individual species contribution to beta diversity for 62 aquatic metacommunity species. I created a series of space-for-time substitution models for species with a high contribution to beta diversity, with a null hypothesis that the spatial and temporal biomass distribution for these species was the same. Long-term data was used to test this space-for-time substitution null hypothesis. Finally, I compared results from these two analyses to test the hypothesis that beta diversity is correlated with space-for-time substitution model validity.

\section{Materials and Methods}

\section{Data Selection}

I used data from two ongoing projects, the Comprehensive Everglades Restoration Plan (CERP) and the Modified Waters Delivery Project (MDW) (Figure 1). 
Both projects sample small-bodied fish, macroinvertebrates, and amphibians from the Greater Everglades ecosystem. Together these projects provide spatiotemporally extensive data ideal for modeling aquatic metacommunity diversity and assessing spacefor-time substitutions. All data were collected with a 1-m2 throw trap following a standard protocol (Jordan et al. 1997).

The CERP project provided a spatially extensive dataset over most of the Everglades Ridge and Slough and Marl Prairie/Rocky Glades ecosystem (Ogden et al. 2003). CERP sampling began in 2005 and continued through 2016. It provides a spatially extensive annual survey based on a Generalized Random Tessellation Stratified (GRTS) sampling design (Stevens and Olsen 2004). The CERP monitoring area covers over 50,000 square kilometers, stretching from Loxahatchee National Wildlife Refuge in the north to the southern reaches of Everglades National Park. The monitoring area for this project was divided into Landscape Sampling Units (LSUs) based on differences in physical landscape characteristics. Each LSU contained several Primary Sampling Units (PSUs); there were a total of 136 PSUs in the CERP monitoring area. During each sampling period, 3 samples are collected at each PSU using a 1-m2 throw trap (Jordan et al. 1997; Trexler et al. 2003). CERP samples were collected once per year late in the South Florida wet season (late September through early December).

The MDW project began in 1996 and provides temporally detailed data from 20 monitoring sites (Trexler et al. 2003). While sampling methods have remained the same over the life of the project, species identification methods have changed in some cases. Early samples were pooled at the site level. Some species that were originally identified 
at the genus level were later recorded as separate species. Because this study includes models for several species, I have truncated MDW sample data to avoid these differences in the spatial and temporal model data sets. MDW samples used for this project were collected between 2005 and 2016. The MDW monitoring area was divided into three regions: Water Conservation Areas (WCA 3A and 3B), Shark River Slough (SRS), and Taylor Slough (TSL). MDW regions overlap, but do not totally cover, the CERP sampling area. Each region in the MDW monitoring area contains several sites, and each site contains 3 plots. Each plot was sampled using methods identical to those used in the CERP project. Samples were collected for the MDW project 5 times per year, creating a temporally robust data set for these 19 monitoring sites $(12$ years $\mathrm{x} 5$ visits per year $=60$ sequential samples per plot).

Physical site conditions including vegetation cover and water depth were recorded during each site visit in both CERP and MDW projects. Water depth field measurements were calibrated using data from the Everglades Depth Estimation Network (EDEN), a US Geological Survey network of 300 water gauges in the CERP sampling area (references for $\mathrm{EDEN})$.

Community metrics, including abundance and wet weight, were calculated for all species collected by throw trap. There was a large disparity between fish and invertebrate abundance in many samples, with invertebrates including Grass shrimp and creeping water bugs often far outnumbering any fish species. However, high abundance alone does not necessarily translate to high environmental impact. This discrepancy therefore caused difficulty with analysis of taxonomically diverse and size-mixed groups. 
To include all species in a single analysis, it was necessary to convert species count data to biomass. Conversions for fish were taken from Kushlan et al. (1986). Formulas for fish species not included in Kushlan et al.'s study were derived from laboratory samples using similar methods. Fish biomass conversion formulas were based on the length of each specimen. Crayfish biomass conversion formulas were taken from Klassen et al. (2014) based on carapace length. Conversion formulas for amphibians and invertebrates other than crayfish were derived by averaging weights for Everglades-collected samples. Conversion formulas were available for most, but not all species (appendix 1). This study included 57 species: 37 fish, 17 invertebrates, and 3 other vertebrates. All study species were found in both CERP and MDW.

Space-for-time models were created for a set of 5 representative species: Marsh Killifish, Bluefin Killifish, Grass Shrimp, Everglades Crayfish, and Slough Crayfish. These species were chosen because of their abundance and contributions to beta diversity.

\section{Quantifying Metacommunity Dynamics through Diversity Analysis}

Beta diversity can be quantified either directionally, as the turnover from one sampling unit to the next along a spatial or environmental gradient, or non-directionally, as the variation among all sampling units (Anderson et al. 2011). For this project, I defined beta diversity as the non-directional total variance of the site-by-species sample matrix (Legendre et al 2005). Beta diversity metrics were analyzed separately for each year using a sums-of-squares approach (Legendre and Caceres 2013) (Figure 2). This 
method has the advantage of being computationally independent from alpha and gamma diversity calculations (Ellison 2010).

Analysis was conducted for the entire CERP dataset and for the Shark River Slough (SRS) and Water Conservation Area 3A (WCA 3A) individual regions.

Analyzing beta diversity at both the project and regional levels allowed for an illustration of the variance in diversity within and throughout the project area. Total Beta Diversity (BDtotal) can range from $0-1$, with 0 reflecting a totally homogeneous region with no difference in species composition or abundance between sites, and 1 representing a region with no common species between sites. The contribution of each species to beta diversity (SCBD) is expressed as a proportion of the total sums-of-squares. Results of this analysis included yearly SCBD metrics for the 57 study species and the yearly BDtotal for the CERP project and individual regions.

\section{Creating Space-for-Time Substitution Models}

A previous study on Bluefin Killifish that used data from the CERP and MDW projects found some support for space-for-time substitution in the Everglades (Banet and Trexler 2013). Models for this earlier study used the number of days since each sample site last experienced a drying event (DSD) as a gradient factor to create chronosequence models. For my study, I selected model species based on their abundance and contribution to beta diversity. Abundance of these model species, as well as all other aquatic metacommunity species, is controlled by a complex and variable combination of hydrological, environmental, and behavioral factors (Sokol et al 2014); hydrological factors like DSD show a strong correlation with abundance for some species and very little correlation with other species. 
In order to test my hypothesis that species contribution to beta diversity is correlated with space-for-time substitution model reliability, I needed to create models that would be applicable for all model species. Because correlation with any gradient factor varies across species, the most generalizable model is one that relies on sample data alone. I therefore elected to create space-for-time substitution models that incorporate only species biomass in lieu of chronosequence models that incorporate an environmental gradient factor for this study.

Space-for-time models were created to compare variance in species biomass in the spatially rich CERP dataset with that of the temporally rich Mod Waters dataset. Chronosequence models by nature require a large spatial aggregate of sample sites over which a gradient factor varies. Because space-for-time substitution relies on the assumption that all sites follow the same development pattern through time (Johnson and Miyanishi 2008), predictions resulting from a valid chronosequence model must be true for each site used in its creation. The models I created tested to see if biomass samples from a large spatial aggregate could be drawn from the same population as a those from a temporal series taken at a single site. The validity of these models can be used to demonstrate the appropriateness of space-for-time substitution in this system. If the variance of biomass at a single site through time does not match that of the spatial aggregate that would be used to create a chronosequence, then the assumption that all sites follow the same developmental pattern is not met.

Previous studies have shown that space-for-time substitutions are more reliable when spatial and temporal data are drawn from the same sampling region (Banet and Trexler 2013). For this reason, when creating space-for-time models, I compared CERP 
data from the Shark River Slough (SRS) and Water Conservation Area 3A regions to MDW data from two representative sites within the same regions. The remaining regions within the CERP sample area either did not contain enough sites for analysis or did not encompass MDW sites for temporal comparison.

Yearly sample sets (2005 - 2016) from two regions of the CERP project, SRS and WCA 3A, were used as the spatial datasets for this analysis. The mean biomass of all throw-trap samples was taken at the PSU level. Because some PSUs could not be sampled because water depth was too deep or shallow, or other prohibitive conditions such as dense or tall vegetation, the total number of yearly samples varied in both regions. A total of 24 spatial datasets ( 2 regions X 12 years) were created.

From the MDW project, two sites were selected from the SRS region and two from the WCA 3A region. MDW sites that did not experience conditions that would periodically prevent sampling, including excessive depth, frequent drying, or overly dense vegetation, were chosen to maximize the continuity of the temporal data samples. MDW samples were averaged at the site level. For each of these sites, all wet-season samples collected from 2005 - 2016 were used to create the temporal datasets. A total of four temporal datasets were created.

For each region, spatial datasets were compared with temporal datasets using the nonparametric Kruskal-Wallis test. This statistic tested whether the spatial and temporal samples were taken from the same population. This process was repeated for each of the five model species, resulting in a total of 240 models. 
To determine whether spatial heterogeneity of species was correlated with reliability of space-for-time substitution in the GE region, I compared SCBD scores with the results of the space-for-time models. Kruskal-Wallis test $p$-values for each space-fortime model were paired with SCBD values for the corresponding model species and CERP region. After pairing, the data were bootstrapped to reduce the effect of outlier values. I then used Pearson's correlation coefficient to analyze the relationship between SCBD and space-for-time substitution model reliability.

\section{Results}

Interannual hydrology varied during the timeframe included in the study, encompassing the full range of wet and dry years typical of the region (Figure 3). Drying events were considered to include any water depth measurements less than $5 \mathrm{~cm}$ at a sampling site. The proportion of sites in the CERP sampling region that experienced at least one drying event during a year (short hydroperiod) varied from a high of over $90 \%$ in 2005 to a low of $18 \%$ in 2016 (Figure 3).

\section{Beta Diversity Analysis}

A total of 157 amphibian, fish, and invertebrate species were identified in MDW and CERP samples. Most of these species were found in both project samples (Figure 4). All of the 57 species used for diversity analysis were present in both project samples. The few species that were found only in CERP may be attributed to the larger sampling region. The species found exclusively in MDW could be related to the extended length of the project or to multi-season sampling. The most abundant fish species were Least Killifish, Heterandria formosa; Eastern Mosquitofish, Gambusia holbrooki; Bluefin 
Killifish, Lucania goodei; and Flagfish, Jordanella floridae. Grass shrimp, Palaemonetes paludosus, and creeping water bugs, Pelocoris femoratus, were the most abundant invertebrates.

Beta diversity in the CERP project area was relatively constant over the life of the program, with $\mathrm{BD}$ total ranging from $0.48-0.65$. $\mathrm{BD}$ total for the $\mathrm{SRS}$ region was between $0.39-0.68$ and $\mathrm{BD}$ total for WCA 3A ranged from $0.32-0.57$ (Figure 5). The grand mean for SCBD in the CERP project area was 0.02. There were 19 species whose mean SCBD scores were above the grand mean (Table 1). These 19 species comprised between 0.734 and 0.913 of the total beta diversity for the CERP region over the life of the project.

Species contribution to beta diversity was correlated with total biomass for most species in the CERP region (Figure 6). This correlation relates higher total biomass to an expectation of higher spatial heterogeneity. Several species were notable outliers in this relationship. Slough Crayfish and Grass Shrimp both have SCBD scores below what would be predicted by biomass alone; these species were less heterogeneous in distribution than would be expected. Bluefin Killifish, Marsh Killifish, and Everglades Crayfish have SCBD scores higher than predicted by biomass alone. These species were chosen as models for space-for-time substitution as they represent highly abundant species whose contribution to beta diversity is either higher or lower than the mean shown through the abundance-diversity relationship.

I analyzed SBCD for each of the model species by year and region (Figure 7). In the SRS region, the Everglades Crayfish showed the most variability in terms of diversity with SCBD of 0.043 in 2009 and 0.167 in 2015 (range $=0.124$ ). In the WCA 3A region, 
the Marsh Killifish had the widest range in SCBD with an SCBD of 0.003 in 2006 and 0.094 in 2008 (range $=0.091)$. The Bluefin Killifish had the smallest range in SCBD in both regions. In the SRS region, Bluefin Killifish SCBD was 0.015 in 2008 and 0.063 in 2013 (range $=0.048)$. In the WCA 3A region Bluefin Killifish SCBD was 0.041 in 2010 and 0.064 in 2014 (range $=0.023$ ). Overall, the WCA 3A region was less variable than the SRS region.

\section{Space-for-Time Substitution Models}

Of the 240 spatial and temporal biomass data combinations, a total of 234 spacefor-time substitution models were created. Six models were dropped because of low sample numbers. In 129 of the 234 models (55\%), the $p$-value for the Kruskal-Wallis test was less than 0.10 , suggesting that the spatial data could be drawn from the same distribution as the temporal data for that model. This was counted as a successful spacefor-time substitution.

The number of successful models was analyzed by species and region (Table 2), and by year (Figure 8). In the WCA 3A region, 60\% of the space-for-time substitution models had Kruskal-Wallis $p$-values less than 0.10 . The SRS region had a $50 \%$ success rate for the space-for-time substitution models. Grass Shrimp yielded the most reliable space-for-time substitution models overall (74\%). The Slough Crayfish was the least reliable (38\%). The proportion of successful models per year ranged from $0.40-0.70$.

\section{Space-for-Time Substitution and Beta Diversity Correlation}

Reliability of the space-for-time substitution models as measured by the KruskalWallis test showed little to no correlation with species contribution to beta diversity 
(SCBD) for four of the five model species. The Pearson correlation coefficient was less than 0.20 for Marsh Killifish, Bluefin Killifish, Everglades Crayfish, and Slough Crayfish. Reliability of the Grass Shrimp models showed moderate correlation with SCBD in the Shark River Slough region with a Pearson correlation coefficient of 0.32 , and high correlation in the Water Conservation Area 3A region with a Pearson correlation coefficient of 0.55 (Figure 9).

\section{Discussion}

Beta diversity metrics varied by year and between regions. The more hydrologically stable Water Conservation Area 3A showed less variability in beta diversity. Previous work has shown that samples from MDW and CERP can be drawn from the same distribution (Smott and Trexler, personal communication 2018). However, models substituting spatial distributions for temporal distributions in these projects were reliable only $50 \%$ to $60 \%$ of the time. Species contribution to beta diversity was not strongly correlated with space-for-time substitution model reliability.

\section{Beta Diversity in the Greater Everglades Aquatic Metacommunity}

BDtotal for the Shark River Slough region ranged from $0.39-0.68$ and was higher and more variable than that of the Water Conservation Area 3A region, which ranged from $0.32-0.57$. Both of these ranges were similar to previous aquatic community beta diversity studies (Legendre et al. 2013). WCA 3A had fewer sites that experienced drying periods and a more regulated yearly hydrological cycle due to water management of the area. This difference in hydrological management may contribute to the lower variability in $\mathrm{BD}_{\text {total }}$ for this sampling region. 
While the CERP aquatic metacommunity includes a large number of species, just 19 of these contribute the bulk of spatial variability in community composition. The sums-of-squares beta diversity analysis method was chosen in part because of its low sensitivity to rare taxa (Anderson et al 2011). The contribution of most species to regional beta diversity can be accurately predicted from species abundance (Figure 7). Species that fall above the line of this abundance-diversity relationship are more heterogeneous in distribution than would be expected from abundance alone. Species that fall under the line are more evenly distributed than would be expected given their abundance. Factors influencing heterogeneity of distribution in aquatic metacommunity species include hydrological cycles and individual species behavior patterns (Sokol et al 2014). More research is needed in this area to understand the environmental drivers that affect the species included in this study.

\section{Space-for-Time Substitution}

The MDW sampling areas are spatially nested within the CERP study sites and sampling methods were identical between the two projects. Previous work by Smott and Trexler (personal communication 2019) has shown that data from these two projects could be drawn from the same distribution for sites within $1.5 \mathrm{~km}$ of each other when examined year-by-year. The models created for this project compared the large spatial area of CERP to the temporally rich MDW data to determine if variability in space and time would change the relationship between these two sample sets.

Space-for-time substitution relies on the assumption that variance across space is equal to variance through time in the absence of driving environmental factors. Therefore, the careful determination of both spatial and temporal scales is essential to 
creating valid space-for-time models. Spatial heterogeneity was one of the reasons identified in my literature review for poor fit in space-for-time substitution models. Because of this, I chose to limit the spatial aggregates used in my models to the region surrounding the sites used for each temporal series. These regions were created based on landscape and hydrological features (Stevens and Olsen 2004). However, both WCA 3A and SRS regions cover several hundred square kilometers and environmental conditions including hydrology and vegetation vary extensively within both regions. The temporal scale of the MDW data used in my models was twelve years, the same length as that of the CERP project.

Overall, space-for-time models created for this project were shown to be valid between $50 \%$ and $60 \%$ of the time. Successful models indicate that environmental drivers were not strong enough to create divergent variances in biomass between the spatial and temporal samples. with substitutions of data from the more hydrologically regulated Water Conservation Area 3A being more reliable than those predicting Shark River Slough data. Individual species models were most reliable for the invertebrate Grass Shrimp, especially in the WCA 3A region, where $96 \%$ of the models created were successful. The two crayfish species yielded the least reliable models.

Success of Bluefin killifish models ranged from $58 \%-63 \%$ in this study. A previous study of space-for-time substitution in the Greater Everglades that also compared CERP and MDW data returned low $R 2$ values, between $0.25-0.30$, for chronosequence models of the relationship between days since dry (DSD) and abundance of Bluefin Killifish (Banet and Trexler 2013). The higher success rate for Bluefin Killifish models in this project was possibly due to the reduced complexity of the model, 
as models for this study were based only on biomass distributions without the inclusion of the second hydrological (DSD) chronosequence factor.

\section{Correlation between Space-for-Time Substitution and Beta Diversity}

A relationship between space-for-time substitutability and beta diversity has been suggested in several studies (Banet and Trexler 2013, Kappes et al 2010). A direct correlation between these variables would be inverse, with higher SCBD being associated with lower space-for-time model validity. Further, a space-for-time model success rate higher than the mean success rate would be expected for species that were more homogeneous in distribution than would be expected by abundance alone and a lower success rate would be expected for species that were more heterogeneous in distribution. In this study, a significant correlation between SCBD and space-for-time model validity was found for only one of the five model species, the Grass Shrimp, in the WCA 3A region. This species also had a model success rate significantly higher than the mean model success rate. Because the Grass Shrimp was one of the species that was less heterogeneous in distribution than predicted by abundance alone, these results support the hypothesis that space-for-time substitutability can be predicted by species contribution to beta diversity when other environmental drivers do not affect distribution of the species. However, the low correlation results and model success rate for the Slough Crayfish, which also falls below the line of the abundance-diversity relationship, and the high model success rate for the Bluefin Killifish, which is highly heterogeneous in distribution, do not support the hypothesis. 


\section{Conclusion}

Space-for-time substitution is useful when employed as a null model to predict trends when the variance in space and time is assumed to be equal (Chapter 1 of this thesis). The successful models in this study support the substitution of spatially extensive biomass data for temporal series data in Grass Shrimp, Bluefin Killifish, and Marsh Killifish. These species would be appropriate candidates for future space-for-time substitution work in the Everglades, especially in the hydrologically managed WCA 3A region. However, because models in this study were broad in both spatial and temporal scale and based on biomass data alone, future work in this area should begin by testing the space-for-time substitutability of hydrological variables associated with each of these species.

Beta diversity analysis shows that space-for-time substitution may be more reliable in regions where environmental factors are more stable and for species that are insensitive to variation in environmental drivers. Creating models to predict real-world data is complex and relies on many interconnected factors. For this reason, space-for-time models should not be used for prediction or management purposes unless the models can first be validated using long-term data.

Future work in this area will expand these models to incorporate more species and to make specific predictions regarding future climate change and land-use scenarios. The methods described here for using space-for-time substitution as a null model can be generalized to projects in different ecosystems. 


\section{References}

Alahuhta, J., J. Luukinoja, H. Tukiainen, and J. Hjort. 2016. Importance of spatial scale in structuring emergent lake vegetation across environmental gradients and scales: GIS-based approach. Ecological Indicators 60:1164-1172

Banet, A., and J. Trexler. 2013. Space-for-Time Substitution Works in Everglades Ecological Forecasting Models. PLoS ONE 8

Bierwagen, BG. 2007. Connectivity in urbanizing landscapes: The importance of habitat configuration, urban area size, and dispersal. Urban Ecosystems 31:234-245

Billings, W. 1938. The Structure and Development of Old Field Shortleaf Pine Stands and Certain Associated Physical Properties of the Soil. Ecological Monographs. $8: 437-500$

Cottenie, K. 2005. Integrating environmental and spatial processes in ecological community dynamics. Ecology letters 8:1175-1182

Elmendorf, S. C., G. H. R. Henry, R. D. Hollister, A. M. Fosaa, W. A. Gould, L. Hermanutz, A. Hofgaard, I. S. Jonsdottir, J. C. Jorgenson, E. Levesque, B. Magnusson, U. Molau, I. H. Myers-Smith, S. F. Oberbauer, C. Rixen, C. E. Tweedie, M. Walker. Experiment, monitoring, and gradient methods used to infer climate change effects on plant communities yield consistent patterns. Proceedings of the National Academy of Sciences of the United States of America. 112:448-452

Fukami, T., D. Wardle. 2005. Long-term ecological dynamics: reciprocal insights from natural and anthropogenic gradients. Proceedings of the Royal Society B: Biological Sciences. 272:2105-2115

Johnson, EA, and K Miyanishi. 2008. Testing the assumptions of chronosequences in succession. Ecology Letters 11:419-431

Jordan, C. F., S. Coyne, and J. C. Trexler. 1997. Sampling fishes in heavily vegetated habitats: the effects of habitat structure on sampling characteristics of the 1-m2 throw trap. Transactions of the American Fisheries Society 126:1012-1020

Kappes H, Sundermann A, Haase P (2010) High spatial variability biases the space-fortime approach in environmental monitoring. Ecological Indicators 10: 1202-1205

Klassen, J.A., D. E. Gawlik, and B. A. Boston. 2014. Length-weight and length-length relationships for common fish and crayfish species in the Everglades, Florida, USA. Journal of Applied Ichthyology. 30:564-566 
Kushlan, James A., et al. 1986. Length, mass, and calorific relationships of Everglades animals. Florida Scientist 1:65-79.

Legendre, Pierre, Daniel Borcard, Pedro R. Peres-Neto. 2005. Analyzing Beta Diversity: Partitioning the spatial variation of community composition data. Ecological Monographs. 75:435-450

Legendre, Pierre and Miquel De Caceres. 2013. Beta diversity as the variance of community data: dissimilarity coefficients and partitioning. Ecology Letters. 16:951-963

Leibold, MA, M Holyoak, and N Mouquet. 2004. The metacommunity concept: a framework for multi-scale community ecology. Ecology Letters 7:601-613

Mbogga, MS, X Wang, and A Hamann. 2010. Bioclimate envelope model predictions for natural resource management: dealing with uncertainty. Journal of applied ecology 47:731-740

Meynard, CN, S Lavergne, and I Boulangeat. 2013. Disentangling the drivers of metacommunity structure across spatial scales. Journal of biogeography 40:15601571

Ogden, J. C., S. M. Davis, and L. A. Brandt. 2003. Science strategy for a regional ecosystem monitoring and assessment program: The Florida Everglades example, pp 135-163 In D. E. Busch and J. C. Trexler, eds. Monitoring Ecosystems. Interdisciplinary Approaches for Evaluating Ecoregional Initiatives. Island Press, Washington DC

Parkos JJ, Trexler JC. 2014. Origins of functional connectivity in a human- modified wetland landscape. Canadian Journal of Fisheries and Aquatic Sciences 1429:1418-1429

Pearlstine, L. G., E. V. Pearlstine, and N. G. Aumen. 2010. A review of the ecological consequences and management implications of climate change for the Everglades. J N Am Benthol Soc 29:1510-1526

Sklar, F. H., M. J. Chimney, S. Newman, P. McCormick, D. Gawlik, S. Miao, C. McVoy, W. Said, J. Newman, C. Coronado, G. Crozier, M. Korvela and K. Rutchey. 2005. The ecological-societal underpinnings of Everglades restoration. Frontiers in Ecology and the Environment 3:161-169

Sokol, ER, JM Hoch, E Gaiser, and JC Trexler. 2014. Metacommunity structure along resource and disturbance gradients in Everglades wetlands. Wetlands 34:S135S146 
Thuiller, W, T Münkemüller, and S Lavergne. 2013. A road map for integrating ecoevolutionary processes into biodiversity models. Ecology letters 16:94-105

Trexler and Goss. 2009. Aquatic fauna as indicators for Everglades restoration: Applying dynamic targets in assessments. Ecological Indicators 9S:S108-S119

Trexler, J. C., W. F. Loftus, and J. Chick. 2003. Setting and monitoring restoration goals in the absence of historical data: The case of fishes in the Florida Everglades, pp 351-376. In D. Busch and J. C. Trexler. Monitoring Ecoregional Initiatives: Interdisciplinary Approaches for Determining Status and Trends of Ecosystems. Island Press

Urban, D, and T Keitt. 2001. Landscape connectivity: a graph-theoretic perspective. Ecology 82:1205-1218

Urban, MC, D. L. Meester, and M Vellend. 2012. A crucial step toward realism: responses to climate change from an evolving metacommunity perspective. Evolutionary applications 5:154-167

Walker, L., A. Wardle, R. Bardgett, B. Clarkson. 2010. The use of chronosequences in studies of ecological succession and soil development. Journal of Ecology. 98:725-736 
Table 1. Species with high Contribution to Beta Diversity (SCBD)

\begin{tabular}{|c|c|c|c|c|c|c|c|c|c|c|c|c|c|}
\hline Scientific Name & Common Name & 2005 & 2006 & 2007 & 2008 & 2009 & 2010 & 2011 & 2012 & 2013 & 2014 & 2015 & 2016 \\
\hline \multicolumn{14}{|l|}{ Cichlasoma } \\
\hline urophthalmus & Mayan Cichlid & 0.083 & 0.020 & 0.041 & 0.024 & 0.075 & & & 0.002 & 0.006 & 0.029 & 0.037 & 0.001 \\
\hline \multicolumn{14}{|l|}{ Enneacanthus } \\
\hline gloriosus & Bluespotted Sunfish & 0.031 & 0.025 & 0.006 & 0.026 & 0.012 & 0.022 & 0.007 & 0.033 & 0.020 & 0.015 & 0.006 & 0.079 \\
\hline Fundulus chrysotus & Golden Topminnow & 0.057 & 0.075 & 0.045 & 0.063 & 0.054 & 0.046 & 0.068 & 0.055 & 0.074 & 0.064 & 0.077 & 0.076 \\
\hline Fundulus confluentus & Marsh Killifish & 0.062 & 0.091 & 0.098 & 0.079 & 0.092 & 0.076 & 0.082 & 0.072 & 0.076 & 0.070 & 0.094 & 0.081 \\
\hline Gambusia holbrooki & Mosquitofish & 0.077 & 0.078 & 0.036 & 0.038 & 0.032 & 0.027 & 0.065 & 0.049 & 0.058 & 0.037 & 0.044 & 0.027 \\
\hline \multicolumn{14}{|l|}{ Hetorandria } \\
\hline Jordanella floridae & Flagfish & 0.081 & 0.063 & 0.079 & 0.067 & 0.085 & 0.058 & 0.072 & 0.067 & 0.078 & 0.069 & 0.065 & 0.036 \\
\hline Lepomis gulosus & Warmouth & 0.015 & 0.009 & 0.018 & 0.035 & 0.040 & 0.056 & 0.017 & 0.036 & 0.019 & 0.004 & 0.010 & 0.022 \\
\hline Lepomis marginatus & Dollar Sunfish & 0.031 & 0.034 & 0.019 & 0.045 & 0.055 & 0.054 & 0.023 & 0.038 & 0.063 & 0.028 & 0.010 & 0.003 \\
\hline Lepomis punctatus & Spotted Sunfish & 0.019 & 0.021 & 0.043 & 0.042 & 0.034 & 0.101 & 0.052 & 0.048 & 0.089 & 0.074 & 0.028 & 0.002 \\
\hline Lucania goodei & Bluefin Killifish & 0.063 & 0.055 & 0.030 & 0.036 & 0.035 & 0.048 & 0.038 & 0.042 & 0.065 & 0.056 & 0.034 & 0.052 \\
\hline
\end{tabular}




\begin{tabular}{|c|c|c|c|c|c|c|c|c|c|c|c|c|c|}
\hline Poecilia latipinna & Sailfin Molly & 0.035 & 0.080 & 0.061 & 0.075 & 0.049 & 0.042 & 0.056 & 0.021 & 0.050 & 0.030 & 0.080 & 0.063 \\
\hline Pomacea paludosa & Applesnail & 0.019 & 0.035 & 0.113 & 0.080 & 0.103 & 0.093 & 0.042 & 0.089 & & 0.054 & 0.023 & 0.027 \\
\hline Belostoma spp. & Giant water bug & 0.012 & 0.022 & 0.018 & 0.013 & 0.014 & 0.014 & 0.046 & 0.010 & 0.017 & 0.011 & 0.052 & 0.022 \\
\hline \multicolumn{14}{|l|}{ Palaemonetes } \\
\hline paludosus & Grass shrimp & 0.061 & 0.050 & 0.049 & 0.050 & 0.048 & 0.028 & 0.026 & 0.044 & 0.056 & 0.028 & 0.028 & 0.046 \\
\hline Procambarus alleni & Everglades crayfish & 0.121 & 0.075 & 0.100 & 0.100 & 0.064 & 0.100 & 0.139 & 0.128 & 0.140 & 0.121 & 0.114 & 0.122 \\
\hline Procambarus fallax & Slough crayfish & 0.059 & 0.050 & 0.050 & 0.030 & 0.038 & 0.042 & 0.082 & 0.043 & 0.061 & 0.050 & 0.050 & 0.046 \\
\hline Rana grylio & Pig Frog & 0.018 & 0.011 & 0.025 & 0.026 & 0.025 & 0.036 & 0.025 & 0.040 & 0.006 & 0.024 & 0.041 & 0.005 \\
\hline Combined SCBD & & 0.879 & 0.822 & 0.847 & 0.846 & 0.876 & 0.855 & 0.856 & 0.840 & 0.913 & 0.790 & 0.823 & 0.734 \\
\hline
\end{tabular}


Table 2. Proportion of models where spatial data could be successfully substituted for temporal data by region and species. $\mathrm{SRS}=$ Shark River Slough; $\mathrm{WCA}=$ Water Conservation Area

SRS WCA 3A Species Average

\begin{tabular}{lccc}
\hline Marsh Killifish & 0.54 & 0.58 & $\mathbf{0 . 5 7}$ \\
Bluefin Killifish & 0.63 & 0.58 & $\mathbf{0 . 6 2}$ \\
Grass Shrimp & 0.50 & 0.96 & $\mathbf{0 . 7 4}$ \\
Everglades Crayfish & 0.46 & 0.33 & $\mathbf{0 . 4 2}$ \\
Slough Crayfish & 0.33 & 0.42 & $\mathbf{0 . 3 8}$ \\
Regional Average & $\mathbf{0 . 5 0}$ & $\mathbf{0 . 6 0}$ &
\end{tabular}




\section{Figure Legends}

Figure 1. Map of Modified Waters Delivery Project (MDW) and Comprehensive Everglades Restoration Plan (CERP) sampling areas

Figure 2. Illustration of the sums-of-squares beta diversity analysis (left) and definitions of variables derived from the analysis (right)

Figure 3. A. Proportion of study sites where the marsh surface dried within the 365 days before sampling plotted by year. B. Maps illustrating PSUs that dried in 365 days before sampling (red dots) and PSUs that did not dry (blue dots) (Trexler 2016)

Figure 4. Greater Everglades Aquatic Metacommunity Species Distribution

Figure 5. Total beta diversity (BDtotal) for Comprehensive Everglades Restoration Plan (CERP) monitoring area, $2005-2016$

Figure 6. Relationship between species biomass and species contribution to beta diversity (SCBD).

Figure 7. Model species contribution to beta diversity in the Shark River Slough (top) and Water .Conservation Area 3A (bottom) from 2005 - 2016.

Figure 8. Proportion of successful space-for-time substitution models by year.

Figure 9. Results of Pearson's correlation coefficient test by model species and region. 


\section{Figure 1.}

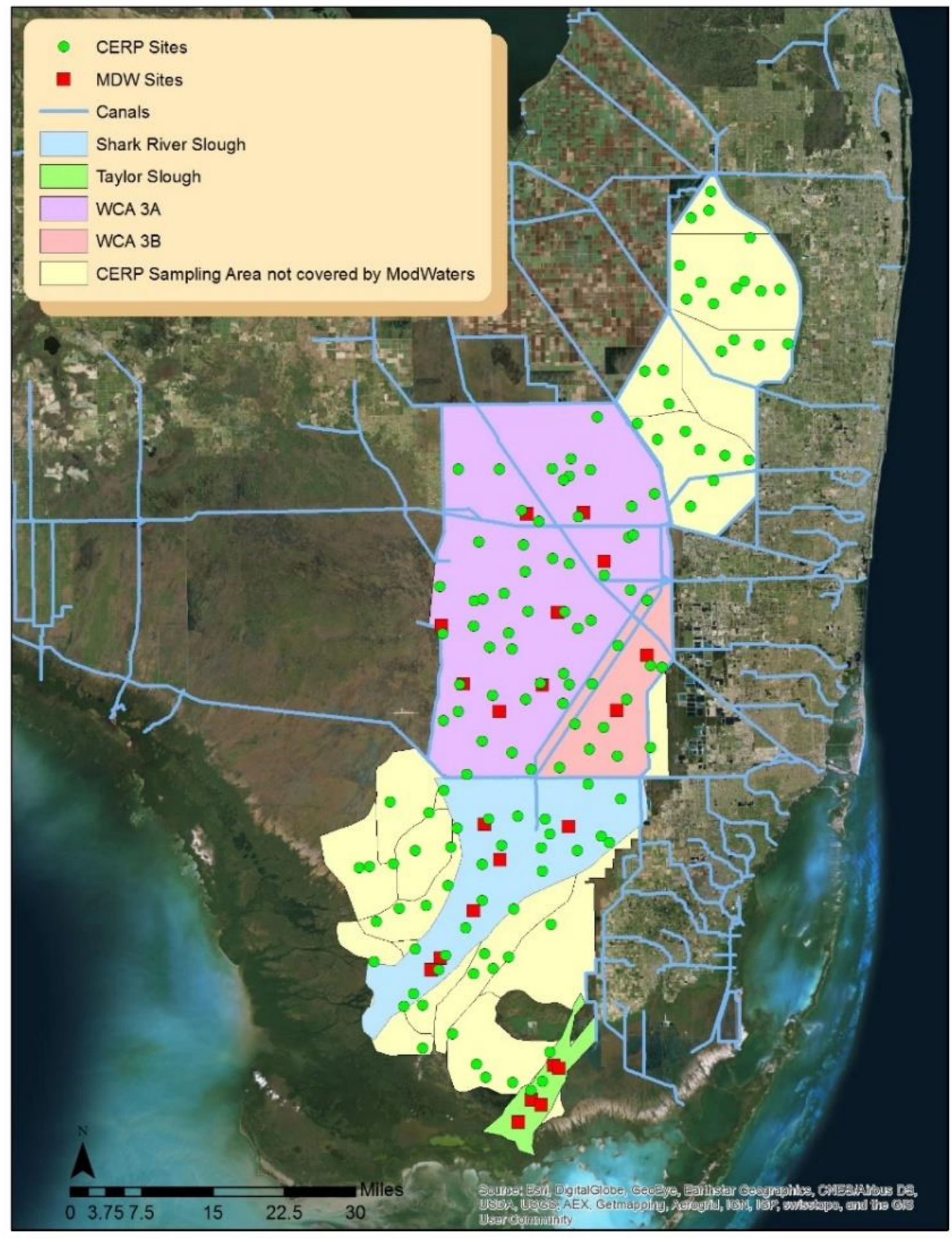


Figure 2.

\section{SPECIES}

\begin{tabular}{|c|c|c|c|c|c|}
\hline & A & B & C & $S S_{i}$ & LCBD \\
\hline 1 & $\mathrm{~S}_{1 \mathrm{~A}}$ & $\mathrm{~S}_{1 \mathrm{~B}}$ & $\mathrm{~S}_{1 \mathrm{c}}$ & $\mathrm{SS}_{1}$ & $\mathrm{LCBD}_{1}$ \\
\hline 2 & $S_{2 A}$ & $S_{2 B}$ & $\mathrm{~S}_{2 \mathrm{C}}$ & $\mathrm{SS}_{2}$ & $\mathrm{LCBD}_{2}$ \\
\hline 3 & $S_{3 A}$ & $\mathrm{~S}_{3 \mathrm{~B}}$ & $\mathrm{~S}_{3 \mathrm{C}}$ & $\mathrm{SS}_{3}$ & $\mathrm{LCBD}_{3}$ \\
\hline $\mathrm{SS}_{\mathrm{j}}$ & $\mathrm{SS}_{\mathrm{A}}$ & $\mathrm{SS}_{\mathrm{B}}$ & $\mathrm{SS}_{\mathrm{C}}$ & $\mathrm{SS}_{\text {total }}$ & \\
\hline SCBD & $\mathrm{SCBD}_{\mathrm{A}}$ & $\mathrm{SCBD}_{\mathrm{B}}$ & $\mathrm{SCBD}_{\mathrm{c}}$ & & $\mathrm{BD}_{\text {total }}$ \\
\hline
\end{tabular}

\begin{tabular}{|l|l|l|}
\multicolumn{1}{|c|}{ Variable } & \multicolumn{1}{c|}{ Definition } & \multicolumn{1}{c|}{ Formula } \\
\hline $\mathbf{S}_{i j}$ & $\begin{array}{l}\text { Squared deviation from } \\
\text { mean species abundance }\end{array}$ & $\left(y_{i j}-\bar{y}_{j}\right)^{2}$ \\
\hline $\mathbf{S S}_{\boldsymbol{i}}$ & $\begin{array}{l}\text { Total of } \mathrm{S}_{i j} \text { values for each } \\
\text { sampling location }\end{array}$ & $\Sigma_{j}^{p} \mathrm{~S}_{i j}$ \\
\hline $\mathbf{L C B D}$ & $\begin{array}{l}\text { Local Contribution to Beta } \\
\text { Diversity }\end{array}$ & $\mathrm{SS}_{i} / \mathrm{SS}_{\text {total }}$ \\
\hline $\mathbf{S S}_{\boldsymbol{j}}$ & $\begin{array}{l}\text { Total of } \mathrm{S}_{i j} \text { values for each } \\
\text { species }\end{array}$ & $\Sigma^{n}{ }_{i=1} \mathrm{~S}_{i j}$ \\
\hline $\mathbf{S C B D}_{i j}$ & $\begin{array}{l}\text { Species Contribution to } \\
\text { Beta Diversity }\end{array}$ & $\mathrm{SS}_{j} / \mathrm{SS}_{\text {total }}$ \\
\hline $\mathbf{S S}_{\text {total }}$ & Total of all $\mathrm{S}_{i j}$ values & $\Sigma^{n}{ }_{i=1} \Sigma^{p}{ }_{j} \mathrm{~S}_{i j}$ \\
\hline $\mathbf{B D}_{\text {total }}$ & Total matrix variance & $\mathrm{SS}_{\text {total }} /(n-1)$ \\
\hline
\end{tabular}


Figure 3.

A

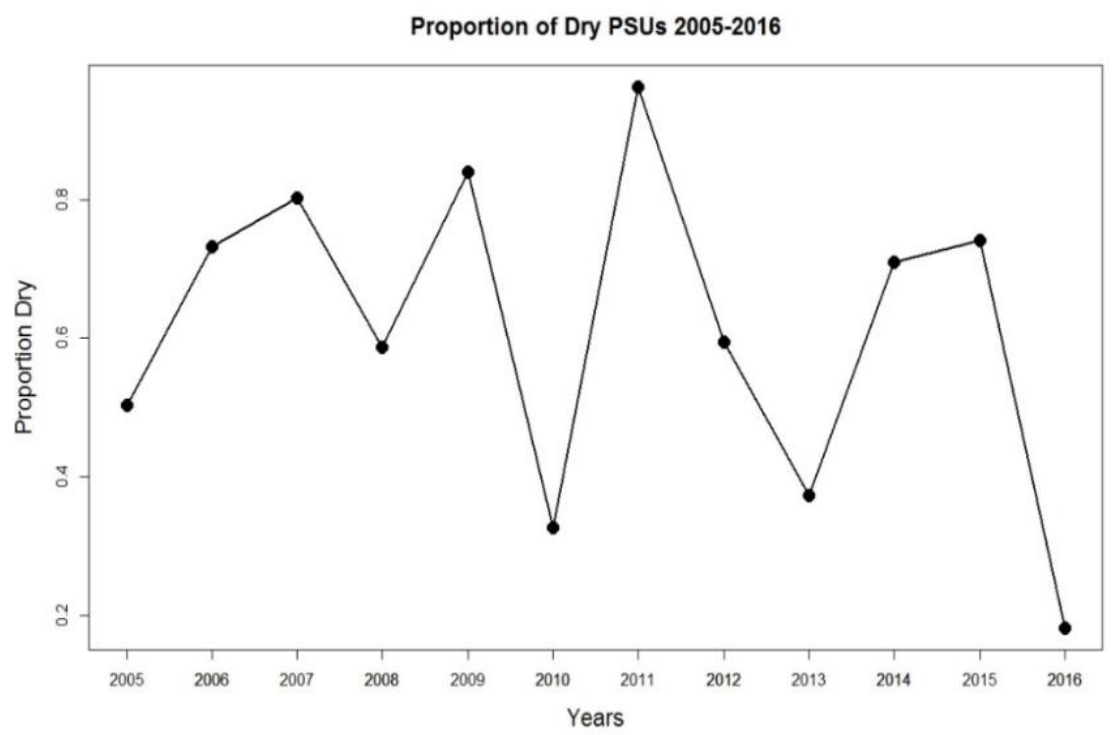

B
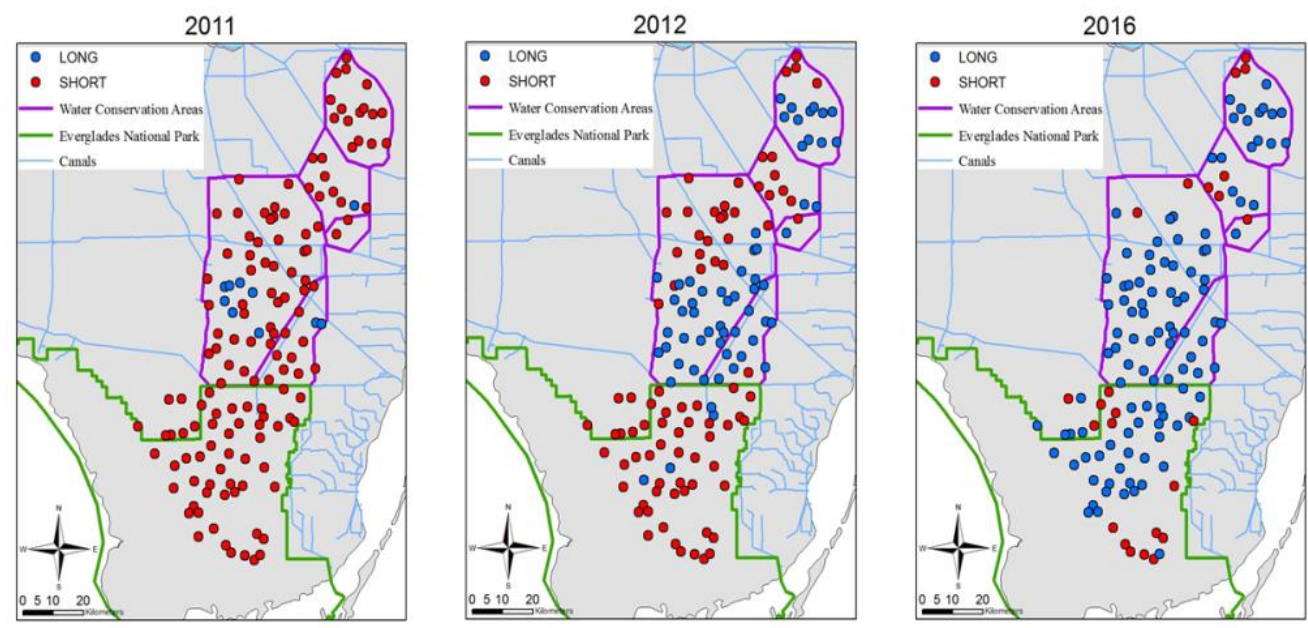
Figure 4.

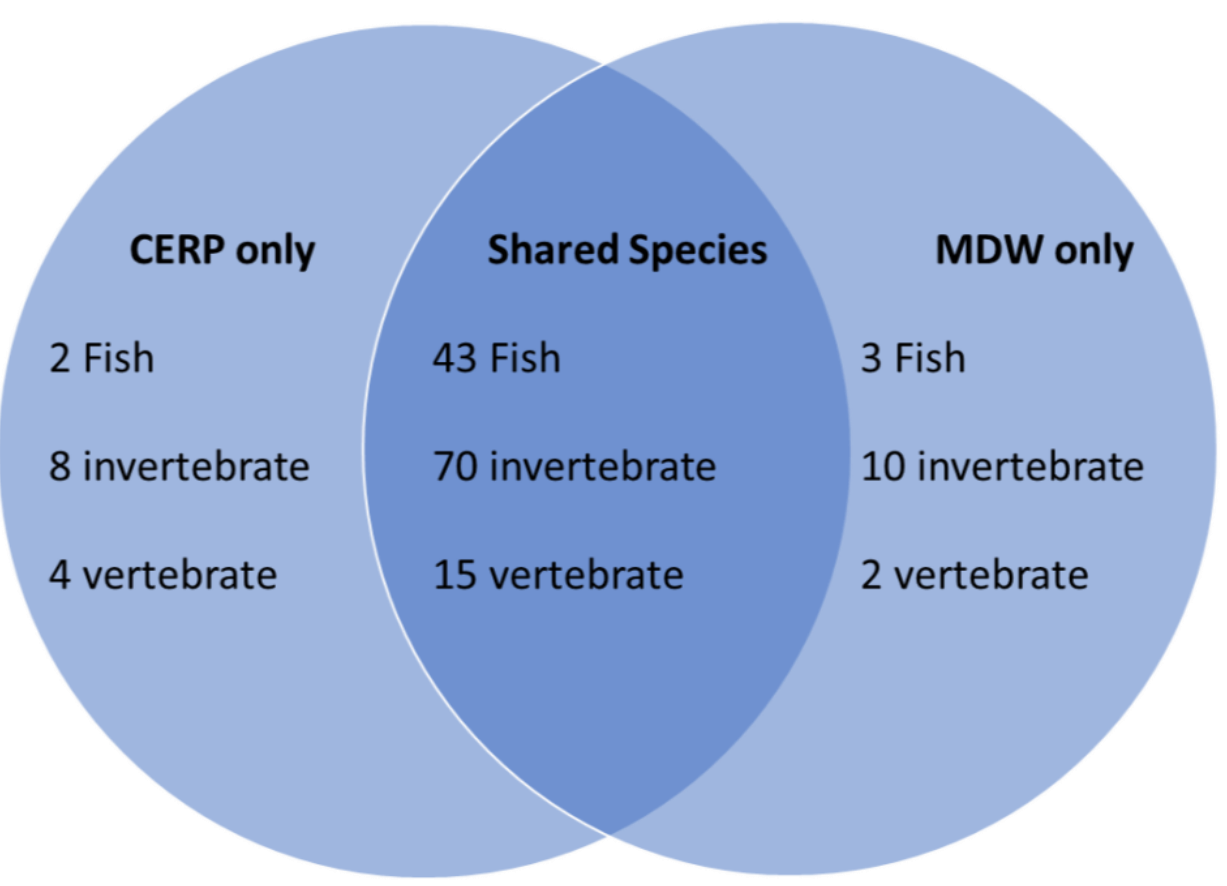


Figure 5.

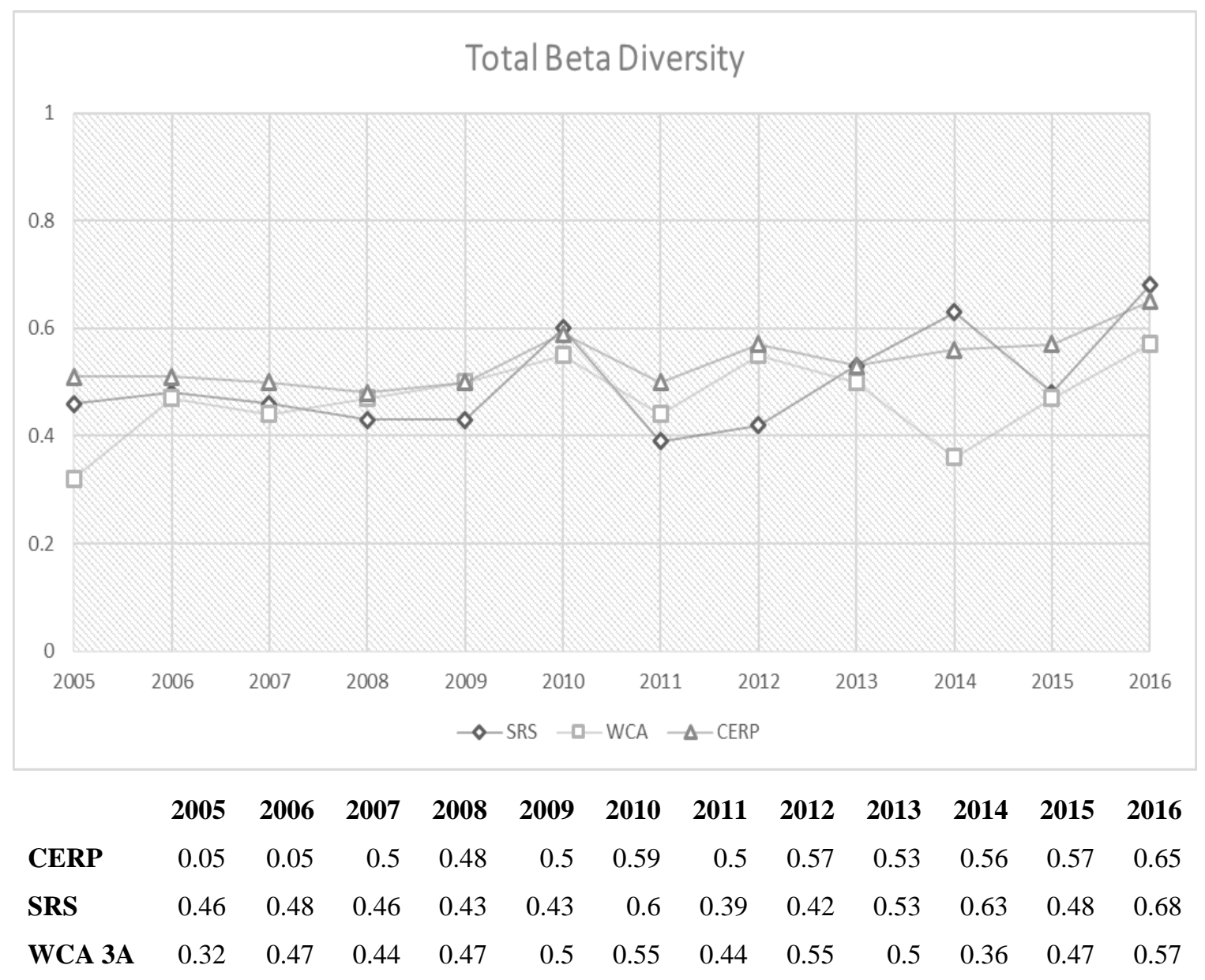


Figure 6.

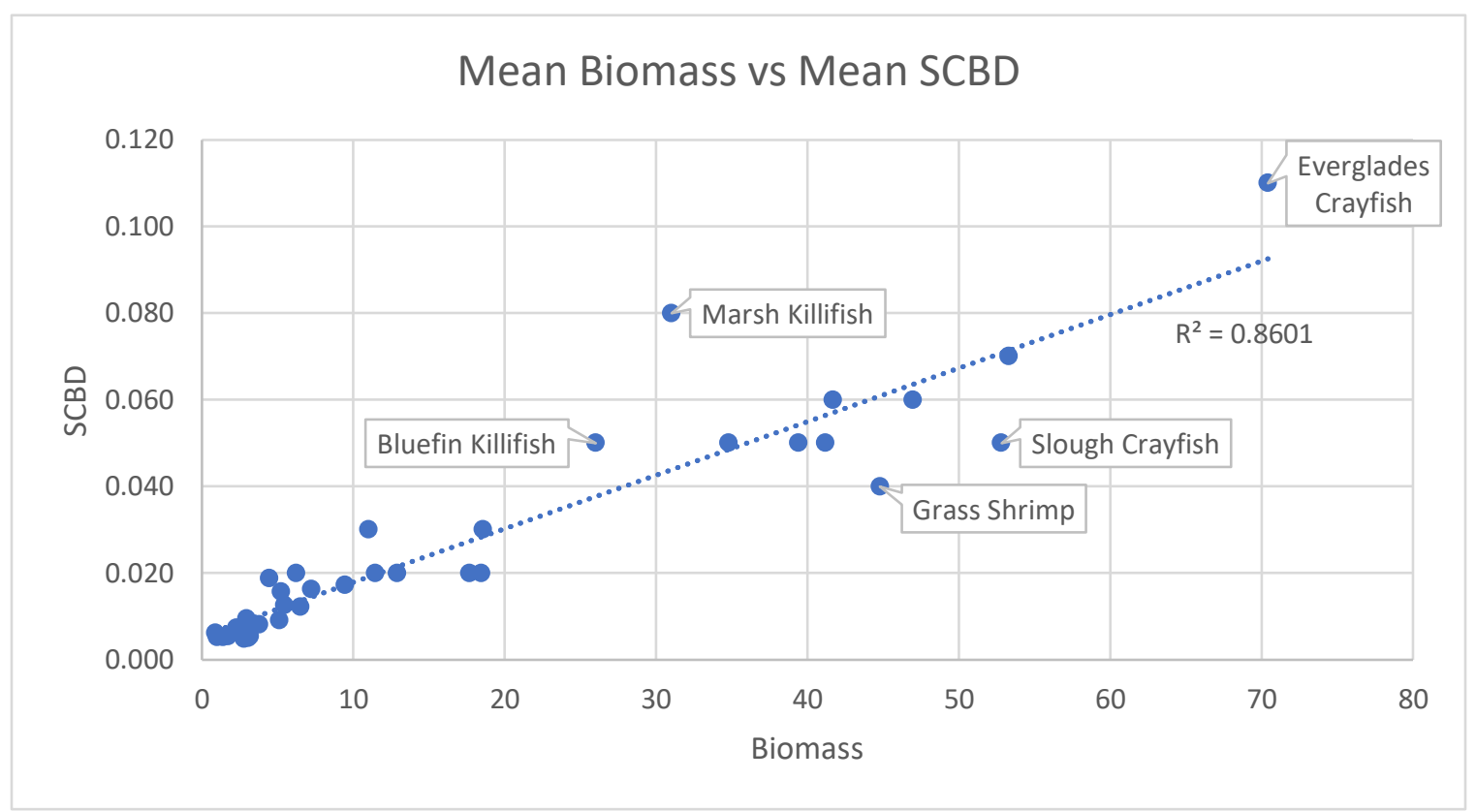


Figure 7.
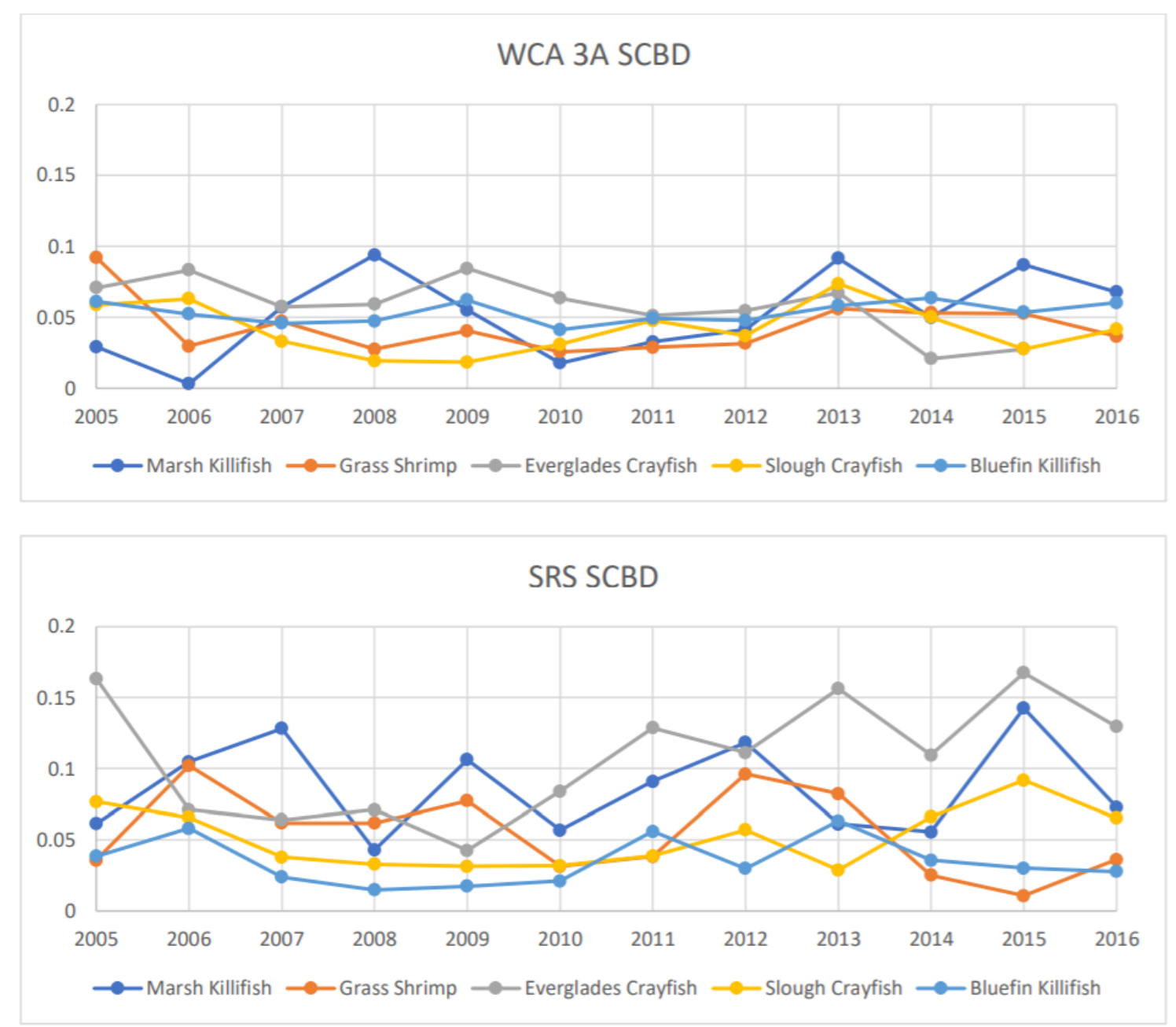
Figure 8.

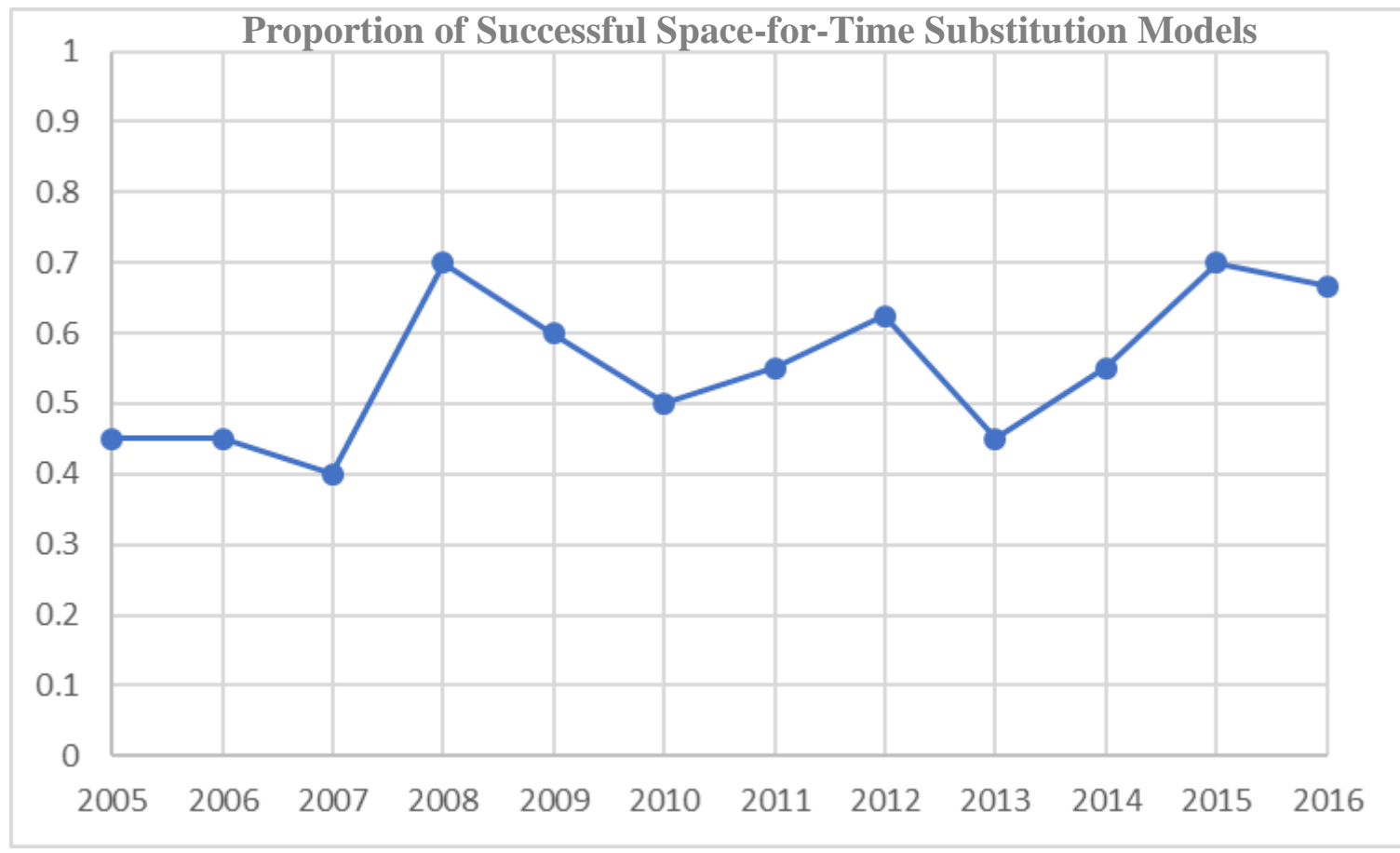


Figure 9.

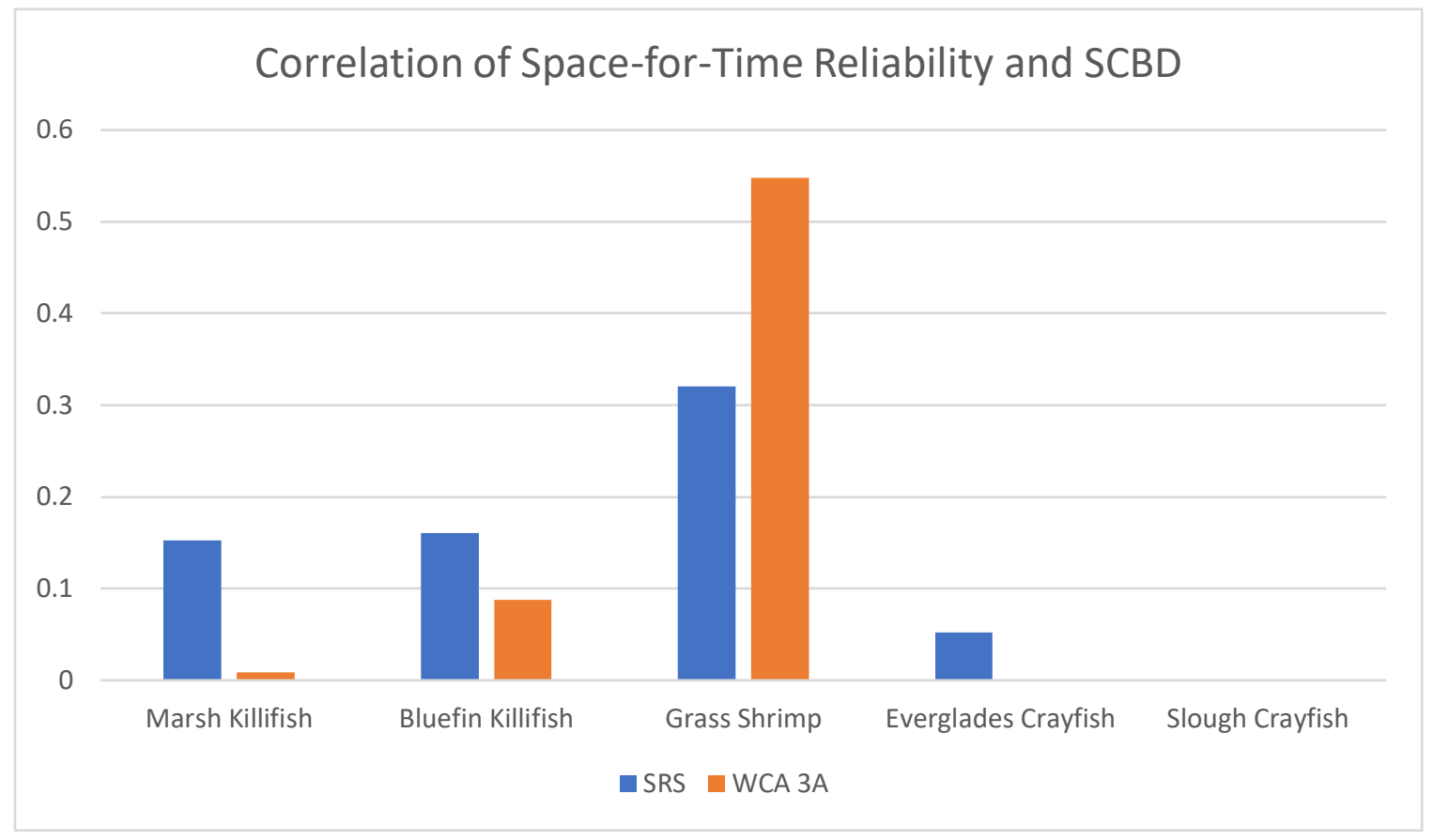


Appendix 1. Biomass conversion formulas for all species included in this study.

\begin{tabular}{|c|c|c|c|c|}
\hline Scientific Name & Common Name & Category & $\begin{array}{c}\text { Conversion } \\
\text { Type }\end{array}$ & Formula $(C=$ count, $L=$ length $)$ \\
\hline Notophthalmus viridescens & Peninsula newt & Amphibian & count & $C \times 0.554954$ \\
\hline Pseudobranchus axanthus & Everglades dwarf siren & Amphibian & count & C $\times 0.2812791667$ \\
\hline Rana grylio & Pig Frog & Amphibian & count & $C \times 0.964577551$ \\
\hline Adinia xenica & Diamond Killifish & Fish & length & $10^{\wedge}\left(-4.987+\left(3.319 \times \log _{10} L\right)\right)$ \\
\hline Ameiurus natalis & Yellow Bullhead & Fish & length & $10^{\wedge}\left(-4.736+\left(3.046 \times \log _{10} L\right)\right)$ \\
\hline Ameiurus nebulosus & Brown Bullhead & Fish & length & $10^{\wedge}\left(-4.736+\left(3.046 \times \log _{10} L\right)\right)$ \\
\hline Aphrododerus sayanus & Pirate Perch & Fish & length & $\left(10^{\wedge}\left(-4.8111+\left(3.225^{*} \times \log _{10} L\right)\right)\right)$ \\
\hline Belonesox belizanus & Pike Killifish & Fish & length & $\left(10^{\wedge}\left(-5.3651+\left(3.2229 \times \log _{10} L\right)\right)\right)$ \\
\hline Cichlasoma bimaculatum & Black Acara & Fish & length & $\left(10^{\wedge}\left(-4.114+\left(2.912 \times \log _{10} L\right)\right)\right)$ \\
\hline Cichlasoma urophthalmus & Mayan Cichlid & Fish & length & $\left(10^{\wedge}\left(-4.7123+\left(3.1259 x \log _{10} L\right)\right)\right)$ \\
\hline Cichlidae species & Cichlid & Fish & length & $\left(10^{\wedge}\left(-4.114+\left(2.912 \times \log _{10} L\right)\right)\right)$ \\
\hline
\end{tabular}




\begin{tabular}{|c|c|c|c|c|}
\hline Clarias batrachus & Walking Catfish & Fish & length & $\left(10^{\wedge}\left(-4.844+\left(2.920 \times \log _{10} L\right)\right)\right)$ \\
\hline Cyprinodon variegatus & Sheepshead Minnow & Fish & length & $\left(10^{\wedge}\left(-5.204+\left(3.543 x \log _{10} L\right)\right)\right)$ \\
\hline Elassoma evergladei & Pygmy Sunfish & Fish & length & $\left(10^{\wedge}\left(-4.581+\left(3.031 x \log _{10} L\right)\right)\right)$ \\
\hline Enneacanthus gloriosus & Bluespotted Sunfish & Fish & length & $\left(10^{\wedge}\left(-4.624+\left(3.113 x \log _{10} L\right)\right)\right)$ \\
\hline Erimyzon sucetta & Lake Chubsucker & Fish & length & $\left(10^{\wedge}\left(-5.236+\left(3.305 x \log _{10} L\right)\right)\right)$ \\
\hline Esox americanus & Grass Pickerel & Fish & length & $\left(10^{\wedge}\left(-5.824+\left(3.243 \times \log _{10} L\right)\right)\right)$ \\
\hline Etheostoma fusiforme & Swamp Darter & Fish & length & $\left(10^{\wedge}\left(-5.686+\left(3.453 x \log _{10} L\right)\right)\right)$ \\
\hline Fundulus chrysotus & Golden Topminnow & Fish & length & $\left(10^{\wedge}\left(-4.876+\left(3.131 x \log _{10} L\right)\right)\right)$ \\
\hline Fundulus confluentus & Marsh Killifish & Fish & length & $\left(10^{\wedge}\left(-4.526+\left(2.887 x \log _{10} L\right)\right)\right)$ \\
\hline Fundulus lineolatus & Lined Topminnow & Fish & length & $\left(10^{\wedge}\left(-4.876+\left(3.131 x \log _{10} L\right)\right)\right)$ \\
\hline Gambusia holbrooki & Mosquitofish & Fish & length & $\left(10^{\wedge}\left(-4.786+\left(3.032 x \log _{10} L\right)\right)\right)$ \\
\hline Hemichromis letourneauxi & Jewel Cichlid & Fish & length & $\left(10^{\wedge}\left(-4.6135+\left(3.0239 \times \log _{10} L\right)\right)\right)$ \\
\hline Heterandria formosa & Least Killifish & Fish & length & $\left(10^{\wedge}\left(-4.837+\left(3.130 \times \log _{10} L\right)\right)\right)$ \\
\hline
\end{tabular}


Hoplosternum littorale

Jordanella floridae

Labidesthes sicculus

Lepomis gulosus

Lepomis macrochirus

Lepomis marginatus

Lepomis microlophus

Lepomis punctatus

Lepomis sp.

Lucania goodei

Lucania parva

Menidia beryllina

Notropis petersoni
Brown Hoplo

Flagfish

Brook Silverside

Warmouth

Bluegill

Dollar Sunfish

Redear Sunfish

Spotted Sunfish

Other Sunfish Species

Bluefin Killifish

Rainwater Killifish

Inland Silverside

Coastal Shiner
Fish

Fish

Fish

Fish

Fish

Fish

Fish

Fish

Fish

Fish

Fish

Fish

Fish

Fish length

length

length

length

length

length

length

length

length

length

length

length

length $\left(10^{\wedge}\left(-4.736+\left(3.046 x \log _{10} L\right)\right)\right)$

$\left(10^{\wedge}\left(-4.643+\left(3.145 \times \log _{10} L\right)\right)\right)$

$\left(10^{\wedge}\left(-5.290+\left(3.075 \times \log _{10} L\right)\right)\right)$

$\left(10^{\wedge}\left(-4.889+\left(3.224 \times \log _{10} L\right)\right)\right)$

$\left(10^{\wedge}\left(-5.100+\left(3.325 x \log _{10} L\right)\right)\right)$

$\left(10^{\wedge}\left(-4.8111+\left(3.225 \times \log _{10} L\right)\right)\right)$

$\left(10^{\wedge}\left(-4.876+\left(3.198 x \log _{10} L\right)\right)\right)$

$\left(10^{\wedge}\left(-4.808+\left(3.222 \times \log _{10} L\right)\right)\right)$

$\left(10^{\wedge}\left(-4.699+\left(3.139 \times \log _{10} L\right)\right)\right)$

$\left(10^{\wedge}\left(-4.782+\left(3.042 \times \log _{10} L\right)\right)\right)$

$\left(10^{\wedge}\left(-4.670+\left(2.980 \times \log _{10} L\right)\right)\right)$

$\left(10^{\wedge}\left(-5.089+\left(3.052 x \log _{10} L\right)\right)\right)$

$\left(10^{\wedge}\left(-5.540+\left(3.443 \times \log _{10} L\right)\right)\right)$ 
Noturus gyrinus

Poecilia latipinna

Tilapia mariae

Belostoma spp.

Brachymesia spp.

Celithemis species

Coryphaeschna ingens

Cybister fimbriolatus

Erythemis species

Family Coenagrionidae

Haitia spp.

Libellula spp

Order Coleoptera
Tadpole Madtom

Fish

Fish

Fish

Spotted Tilapia

Giant water bug

Invertebrate

count

\section{Regal darner}

Predaceous diving beetle

Pondhawk

Damselfly larvae

Physid snail

Skimmer

Aquatic beetles count

count

count

Invertebrate

Invertebrate

Invertebrate

count

count

count

count

count

count
Invertebrate $\left(10^{\wedge}\left(-4.552+\left(2.947 \times \log _{10} L\right)\right)\right)$

$\left(10^{\wedge}\left(-4.750+\left(3.142 \times \log _{10} L\right)\right)\right)$

$\left(10^{\wedge}\left(-4.114+\left(2.912 \times \log _{10} L\right)\right)\right)$

C $\times 0.1643188312$

C $\times 0.0480775862$

C $\times 0.0494062112$

C $\times 0.3084865385$

C $\times 0.2546416667$

C $\times 0.0617573529$

$C \times 0.0116$

C $\times 0.009256106$

C $\times 0.1241988095$

C $x 0.0277158537$ 
Palaemonetes paludosus

Pelocoris femoratus

Planorbella spp.

Pomacea paludosa

Procambarus alleni

Procambarus fallax

Order Ephemeroptera

$\begin{array}{cllc}\text { Grass shrimp } & \text { Invertebrate } & \text { count } & C \times 0.0575045829 \\ \text { reeping water bug } & \text { Invertebrate } & \text { count } & C \times 0.0228193431 \\ \text { planorbid snail } & \text { Invertebrate } & \text { count } & C \times 0.117557626 \\ \text { Apple snail } & \text { Invertebrate } & \text { count } & C \times 8.329981322 \\ \text { Everglades crayfish } & \text { Invertebrate } & \text { length } & 0.217 \times(\mathrm{L} / 10)^{\wedge} 2.85 \\ \text { Slough crayfish } & \text { Invertebrate } & \text { length } & 0.192 \times(\mathrm{L} / 10)^{\wedge} 3.03 \\ \text { Mayfly larvae } & \text { Invertebrate } & \text { count } & C \times 0.0048830189\end{array}$

